\title{
Rubidium chloride modulated the fecal microbiota community in mice
}

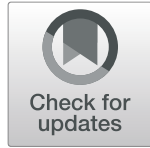

\author{
Qian Chen ${ }^{1 \dagger}$, Zhiguo He${ }^{2 \dagger}$, Yuting Zhuo', Shuzhen $\mathrm{Li}^{2}$, Wenjing Yang ${ }^{2}$, Liang $\mathrm{Hu}^{2}$ and Hui Zhong ${ }^{1 *}$
}

\begin{abstract}
Background: The microbiota plays an important role in host health. Although rubidium (Rb) has been used to study its effects on depression and cancers, the interaction between microbial commensals and $\mathrm{Rb}$ is still unexplored. To gain the knowledge of the relationship between $\mathrm{Rb}$ and microbes, 51 mice receiving RbCl-based treatment and 13 untreated mice were evaluated for their characteristics and bacterial microbiome changes.

Results: The $16 \mathrm{~S}$ ribosomal RNA gene sequencing of fecal microbiota showed that $\mathrm{RbCl}$ generally maintained fecal microbial community diversity, while the shifts in fecal microbial composition were apparent after $\mathrm{RbCl}$ exposure. $\mathrm{RbCl}$ significantly enhanced the abundances of Rikenellaceae, Alistipes, Clostridium XIVa and sulfate-reducing bacteria including Deltaproteobacteria, Desulfovibrionales, Desulfovibrionaceae and Desulfovibrio, but significantly inhibited the abundances of Tenericutes, Mollicutes, Anaeroplasmatales, Anaeroplasmataceae and Anaeroplasma lineages. With regarding to the archaea, we only observed two less richness archaea Sulfolobus and Acidiplasma at the genus level.

Conclusions: Changes of fecal microbes may in part contribute to the anticancer or anti-depressant effects of RbCl. These findings further validate that the microbiome could be a target for therapeutic intervention.
\end{abstract}

Keywords: Fecal microbial community, Rubidium (Rb), Microbiome, Anticancer, Anti-depressant

\section{Background}

Rubdium $(\mathrm{Rb})$ is found in air, soil, water and organisms, and is a less studied alkali metal element and can efficiently transfer to the human body through the food chain (soilplant-human) [1]. Since the first report on its correlation with phenylketonuria and maple-syrup-urine disease [2], some studies have suggested its effects on tumor [3, 4], depression [5-7] and cardiovascular system [8].

Researchers found that many cancers were caused by the changes of $\mathrm{Rb}^{+}$levels in the body $[3,9]$. Some other studies have shown that $\mathrm{Rb}$ was easily taken up by cancer cells and might affect the proliferation of cancer cells $[4,10]$. There are several studies reporting that $\mathrm{Rb}$ could be used to treat depression [11, 12]. Later studies confirmed that $\mathrm{Rb}$ decreased the depression-like behavior

\footnotetext{
* Correspondence: hmmzhij@csu.edu.cn

${ }^{+}$Qian Chen and Zhiguo He contributed equally to this work.

${ }^{1}$ School of Life Sciences, Central South University, Changsha 410013, China

Full list of author information is available at the end of the article
}

via nitric oxide (NO) pathway [7]. Although there are some hypotheses about the mechanisms of anticancer or anti-depressant of $\mathrm{Rb}$, none of them provided sufficiently reliable evidence.

The microbiome is a dynamic ecological community which mainly includes bacteria, archaea, fungi and viruses [13]. There is growing evidence proving that the microbiome plays key roles in the cancer and neurological disease [14-17]. During recent years, the potential role of the microbiome in various human diseases has attracted the attention of researchers [13, 18]. Many diseases, including cancer and depression, are related to the imbalance of the microbial community. Recent studies reported that the microbial community of colorectal cancer (CRC) patients was significantly different from that of healthy individuals [19]. These specific species of the microbiota, such as Fusobacterium nucleatum, Enterococcus faecalis, Bacteroides fragilis, and Escherichia coli, etc., were enriched in the stool of CRC patients and 
promoted the development of CRC [20]. Some researchers reported that specific microorganisms, including Firmicutes and Bacteroidetes, might be involved in the occurrence and the development of depression [21]. Meanwhile, Lactobacillus and Bifdobacterium were reported to be beneficial to the treatment of depression [22, 23].

However, to our best knowledge, no work has been reported on the effect of chemical element $\mathrm{Rb}$ on the microbiome, and whether $\mathrm{Rb}$ inhibits tumor and depression thorough changing the community composition of microbiome is still not clarified. Therefore, the present study was to investigate the relationship between the addition of rubidium chloride $(\mathrm{RbCl})$ and composition of fecal microbiome in order to further understand the mechanism of $\mathrm{Rb}$ against cancer and neurological disease from the perspective of fecal microbial community.

\section{Results}

\section{Effect of $\mathrm{RbCl}$ on animal characteristics}

To better understand the effects of $\mathrm{RbCl}$ on mice, we conducted a follow-up study of 64 mice and recorded body weights and multiple organ weights of each mouse. Changes of the body weights in all the groups were shown in Fig. 1a. The weights of mice in the drug groups decreased when compared with mice in control group and were negatively correlated with dosage whereas these differences were not statistically significant. Additionally, multiple organ coefficients were observed (Fig. 1b). Interestingly, as $\mathrm{RbCl}$ concentration was increased, the organ coefficient of stomach gradually decreased. However, there was an increase in organ coefficients among other organs such as pancreatic, spleen, kidneys, lungs and heart. Changes of gastric organ coefficient during drug administration could be explained by route of administration. These data indicated that $\mathrm{RbCl}$ had little effect on animal characteristics.

\section{Effect of $\mathrm{RbCl}$ on the fecal microbial communities}

From the results of $16 \mathrm{~S}$ rRNA gene sequencing, we obtained a total of 1,481,388 high-quality reads for 64 fecal samples of four groups, which could be clustered into 486 OTUs. Figure 3a indicates the rarefaction curves of all samples. The curves tended to be flat as the number of extracted sequences increased, indicating that the sequencing depths included most of the microbes in samples. As shown in Fig. 2, the indices reflecting community richness include Sobs, Chao and Ace. The indices reflecting community diversity are Shannon and Simpson. The richness and diversity indexes demonstrated no statistical differences in control, low-dose (Chao, $P=0.9401$; Sobs, $P=0.5239$; Ace, $P=0.7497$; Shannon, $P=0.5082$; Simpson, $P=0.5401$ ), middle-dose (Chao, $P=0.6578$; Sobs, $P=0.7346$; Ace, $P=0.7640$; Shannon, $P=0.8858$; Simpson, $P=0.5176)$ and highdose groups (Chao, $P=0.7105$; Sobs, $P=0.3809$; Ace, $P=0.7243$; Shannon, $P=0.8954$; Simpson, $P=0.4176$ ). In addition, to assess the effect of the different treatments on the assembly of bacterial communities, we compared the $\beta$-diversity (between-samples diversity) using Bray Curtis distances and performed constrained principal coordinate analysis (CPCoA). This analysis revealed a clear differentiation of samples belonging to the control, low-dose, middle-dose, and high-dose groups that explained as much as $6.62 \%$ of the overall variance of the data (Fig. 3b; $P<0.001$ ). Thus, the above results showed that $\mathrm{RbCl}$ did not affect the diversity and

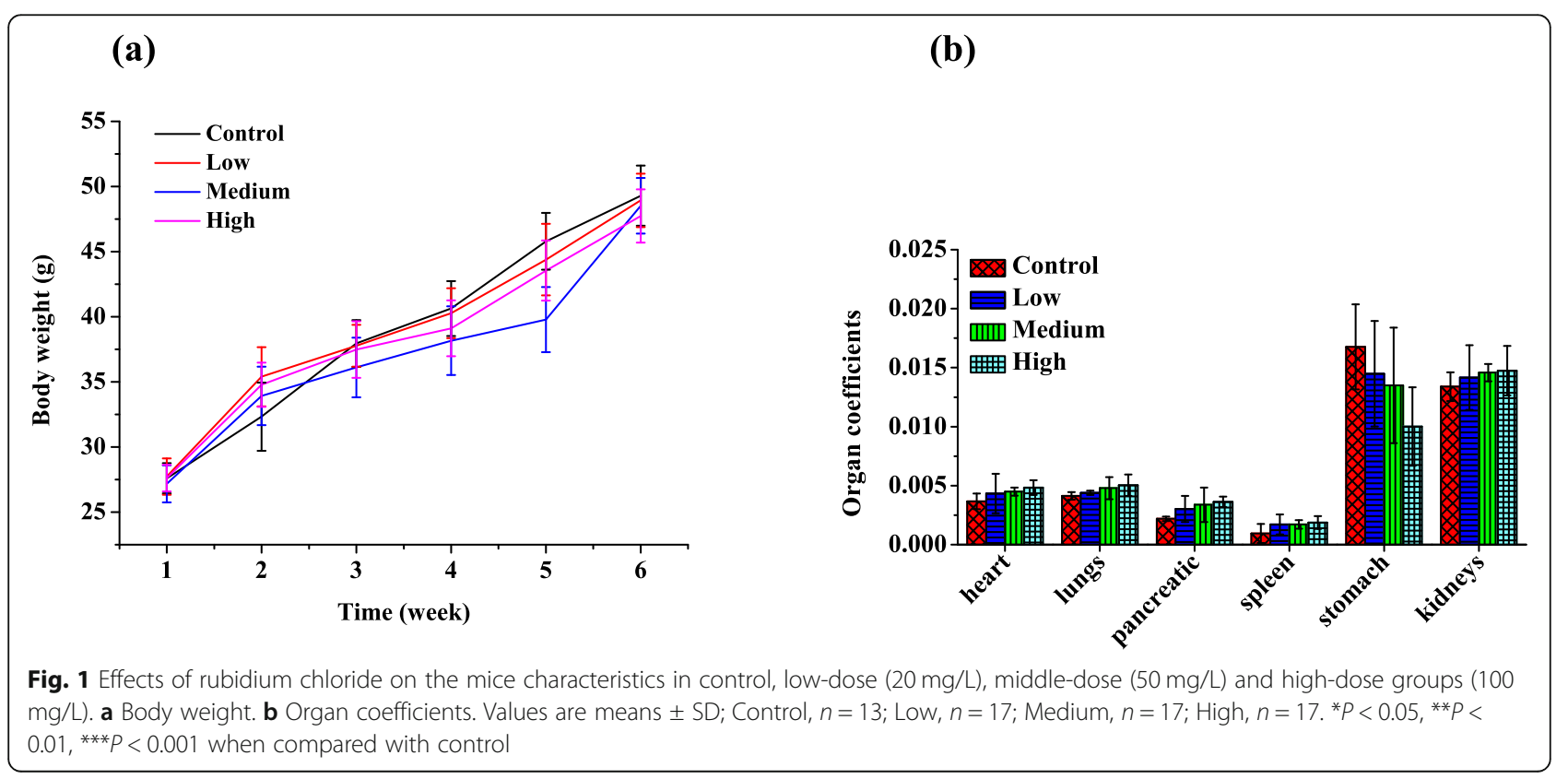




\section{(a)}

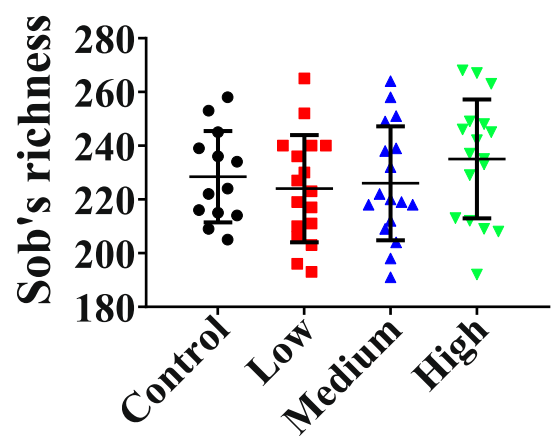

(c)

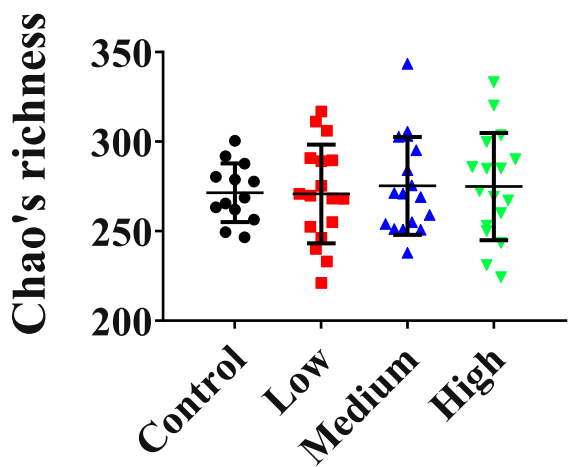

(e)

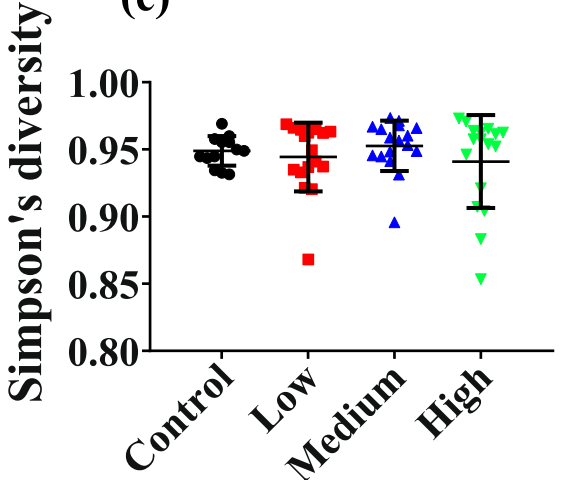

(b)

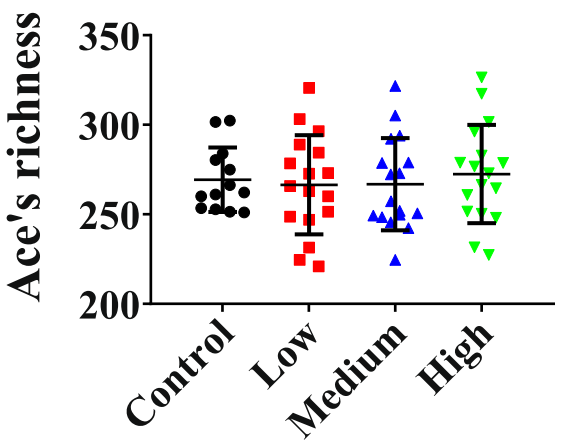

(d)

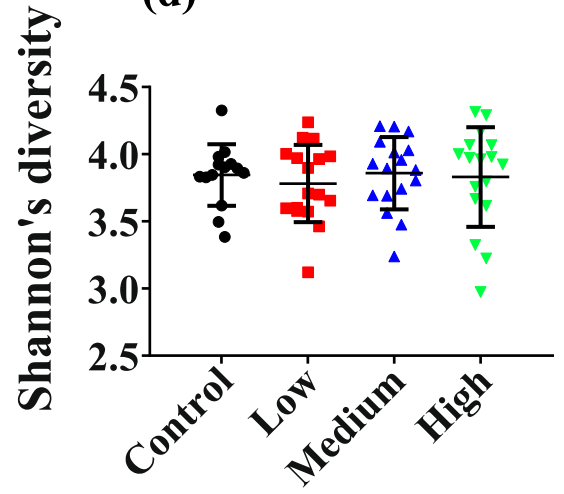

Fig. 2 The diversity and richness of samples collected from 64 mice; a Sob's richness; b Ace's richness; c Chao's richness; d Shannon's diversity; e Simpson's diversity

richness of the fecal microbial community in general. However, it altered the structure of the fecal bacterial community, reflected in changes in fecal microbial composition.

\section{Effect of $\mathrm{RbCl}$ on fecal bacterial composition}

All OTUs were clustered into 12 phyla, 19 classes, 27 orders, 44 families, 92 genera. The venn diagram (Fig. S1) showed 352 shared OTUs among all the fecal samples, and samples in control, low-dose, middle-dose and highdose groups had 7, 14, 8 and 10 unique OTUs, respectively. Results indicated that although the proportion of shared microbial communities was very high, distinct microbial communities still existed in different treatment groups. Compositions of fecal bacteria in all samples were determined using $16 \mathrm{~S}$ rRNA gene sequencing. The fecal microbial compositions of phylum with relative abundance above 5\% were seen in Fig. 4. Other microorganisms with relative abundance less than $5 \%$ were shown in Table. S1. In all samples, Firmicutes was the dominant phylum with average abundances of 51.03, $50.18,47.15$ and $43.73 \%$ in control, low-dose, middle-dose 
(a)

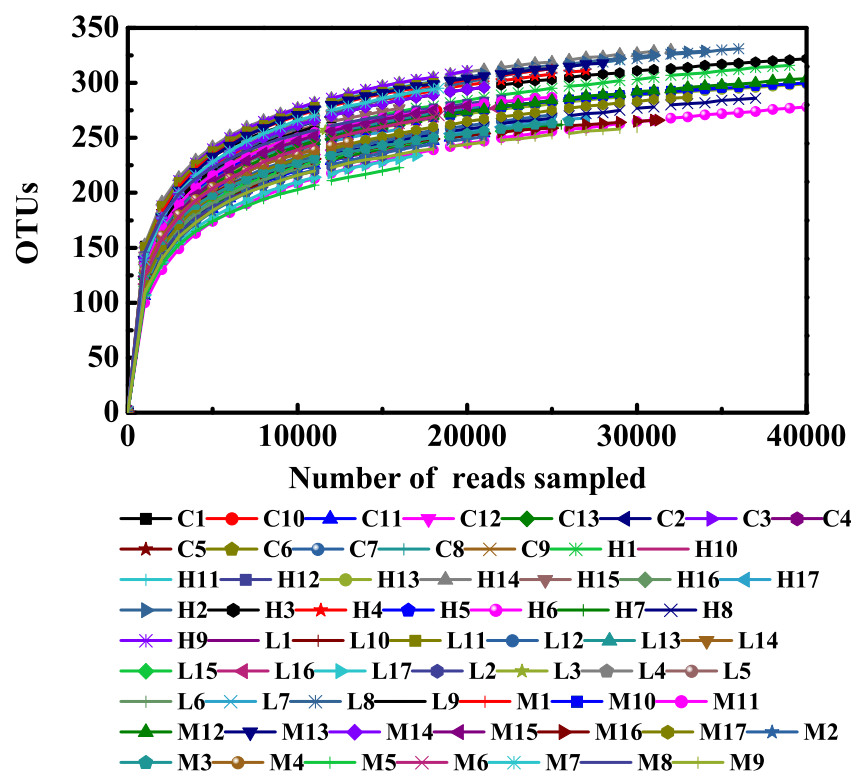

(b)

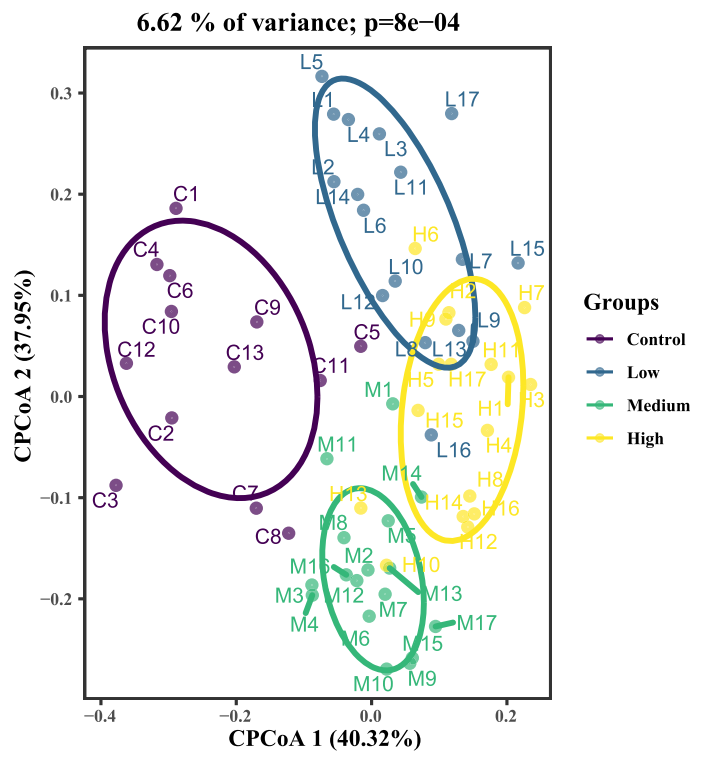

Fig. 3 Variations of microbial communities in four groups. a Rarefaction curves of the samples; $\mathbf{b}$ Constrained PCoA plots of Bray-Curtis distances among the four groups

and high-dose groups, respectively (Fig. 5a). The relative abundances of Bacteroidetes, the second dominant phylum, were not significantly different among the four groups (Fig. 5b). Moreover, less richness Tenericutes (the average abundances were $0.86,0.23,0.05$ and $0.08 \%$ ) and Actinobacteria (the average abundances were $0.03,0.03$, 0.04 and $0.07 \%$ ) were observed in control, low-dose, middle-dose and high-dose groups, respectively (Table. S1). As shown in Fig. 5c and d, enrichment of Actinobacteria and depletion of Tenericutes $(P<0.01)$ were correlated with high doses of $\mathrm{RbCl}$.

The fecal microorganisms from four groups were separated into 3 dominant classes including Bacteroidia, Clostridia and Epsilonproteobacteria (Fig. 6). Other classes

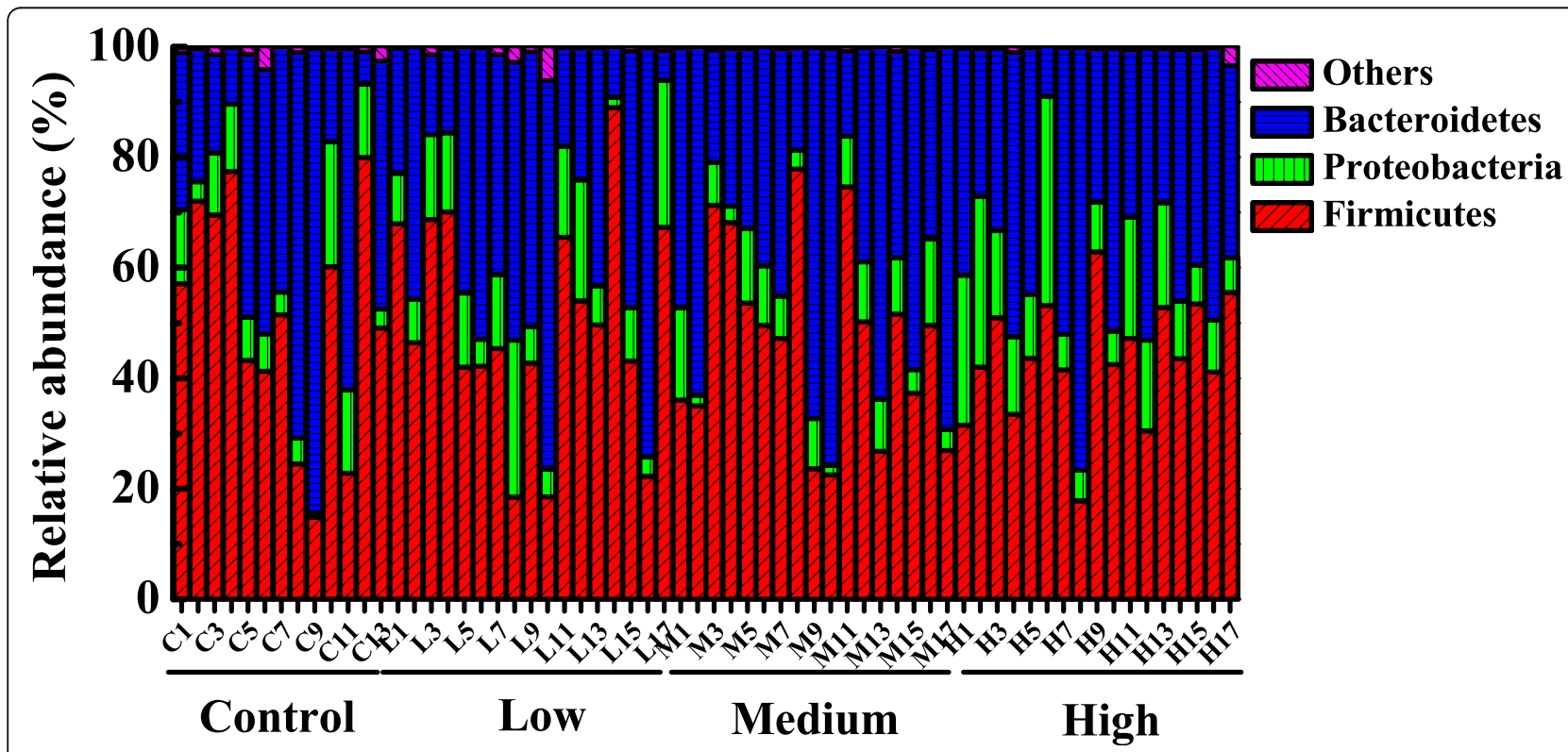

Fig. 4 Relative abundance of fecal microorganisms at the phylum level, different colors represent different microbe. "Others" represents the microbes with relative abundance less than $5 \%$ 
(a)

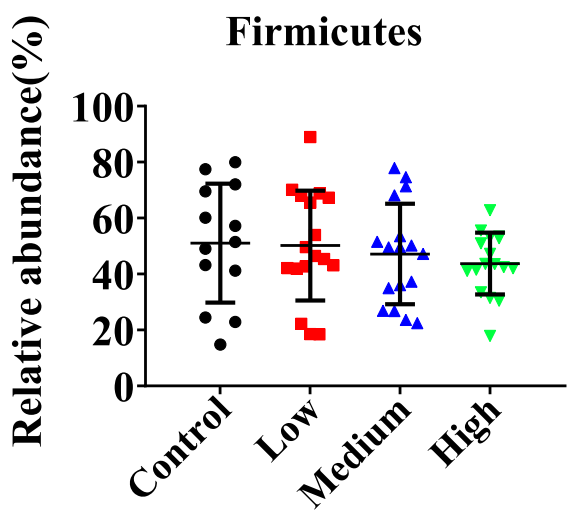

(c)

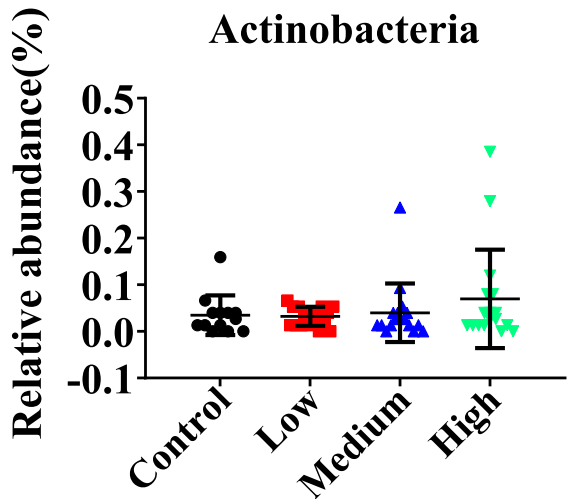

(b)

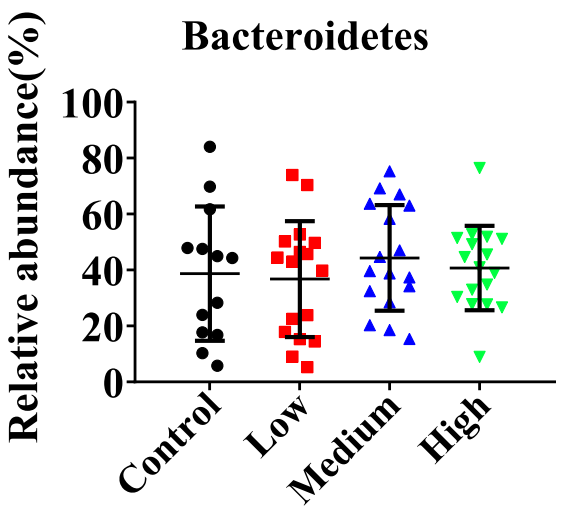

(d)

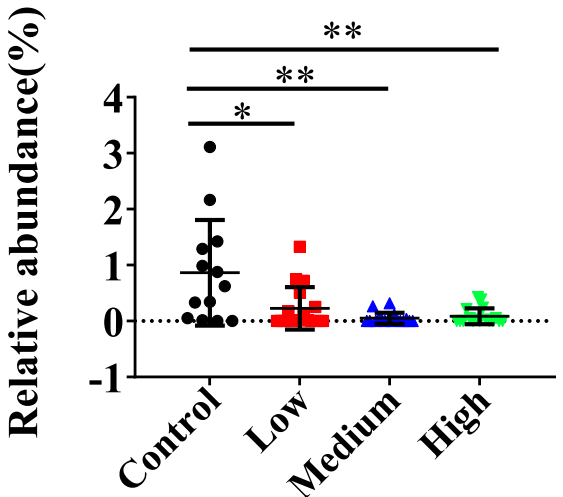

Fig. 5 Statistical analysis of relative abundance of fecal bacteria at the phylum level. a The abundances of Firmicutes were not significantly altered among four groups. $\mathbf{b}$ The abundances of Bacteroidetes showed no statistical differences among four groups. $\mathbf{c}$ The abundances of Actinobacteria showed no statistical differences among four groups. $\mathbf{d}$ The abundances of Tenericutes were significantly lower in $\mathrm{RbCl}$ groups $(P<0.05)$ than the control group. Data are shown as mean $\pm \mathrm{SD}$. ${ }^{*} P<0.05,{ }^{* *} P<0.01,{ }^{* * *} P<0.001$

with relative abundance less than $5 \%$ were shown in Table S2. Statistically significant differences between the experimental groups and the control group were also performed in our study. The abundances of Deltaproteobacteria were significantly higher in three experimental groups $(P<0.05)$ than those of the control (Fig. 7a). In addition, differences in the relative abundances of Mollicutes were significant in control, low-dose $(P=0.0175)$, middle-dose $(P=0.0014)$ and high-dose groups $(P=0.0022)$ (Fig. 7b).

The fecal microbes with relative abundance above $5 \%$ at the level of order were shown in Fig. 8. A total of 27 orders were observed in all samples (Table. S3). The relative proportion of Anaeroplasmatales was significantly increased in control group $(P<0.05)$ (Fig. 9a), while the abundance of Desulfovibrionales was significantly higher in low-dose $(P=0.0176)$, middle-dose $(P=$ $0.0219)$ and high-dose groups $(P=0.0033)$ than control group (Fig. 9b).
At the family level, fecal microbes with relative abundance above $5 \%$ were shown in Fig. 10. Others families with relative abundance less than $5 \%$ were observed in Table. S4. Among these families, the abundance of Anaeroplasmataceae was found significantly higher in control group $(P<0.05)$ than three experimental groups (Fig. 11a), while the abundances of Desulfovibrionaceae were significantly increased in three experimental groups $(P<0.05)$ (Fig. 11b). Besides, compared with the control group, the abundances of Rikenellaceae significantly increased in low-dose $(P<0.0006)$, middle-dose $(P<0.0054)$ and high-dose groups $(P<0.0033)$ (Fig. 11c).

Figure 12 showed the microbial compositions with relative abundance above $5 \%$ at the genus level. The microbial community compositions were similar but relative abundances of genera varied. OTUs unclassified at the genus level were the most abundant and there were no statistical significant differences among all fecal 


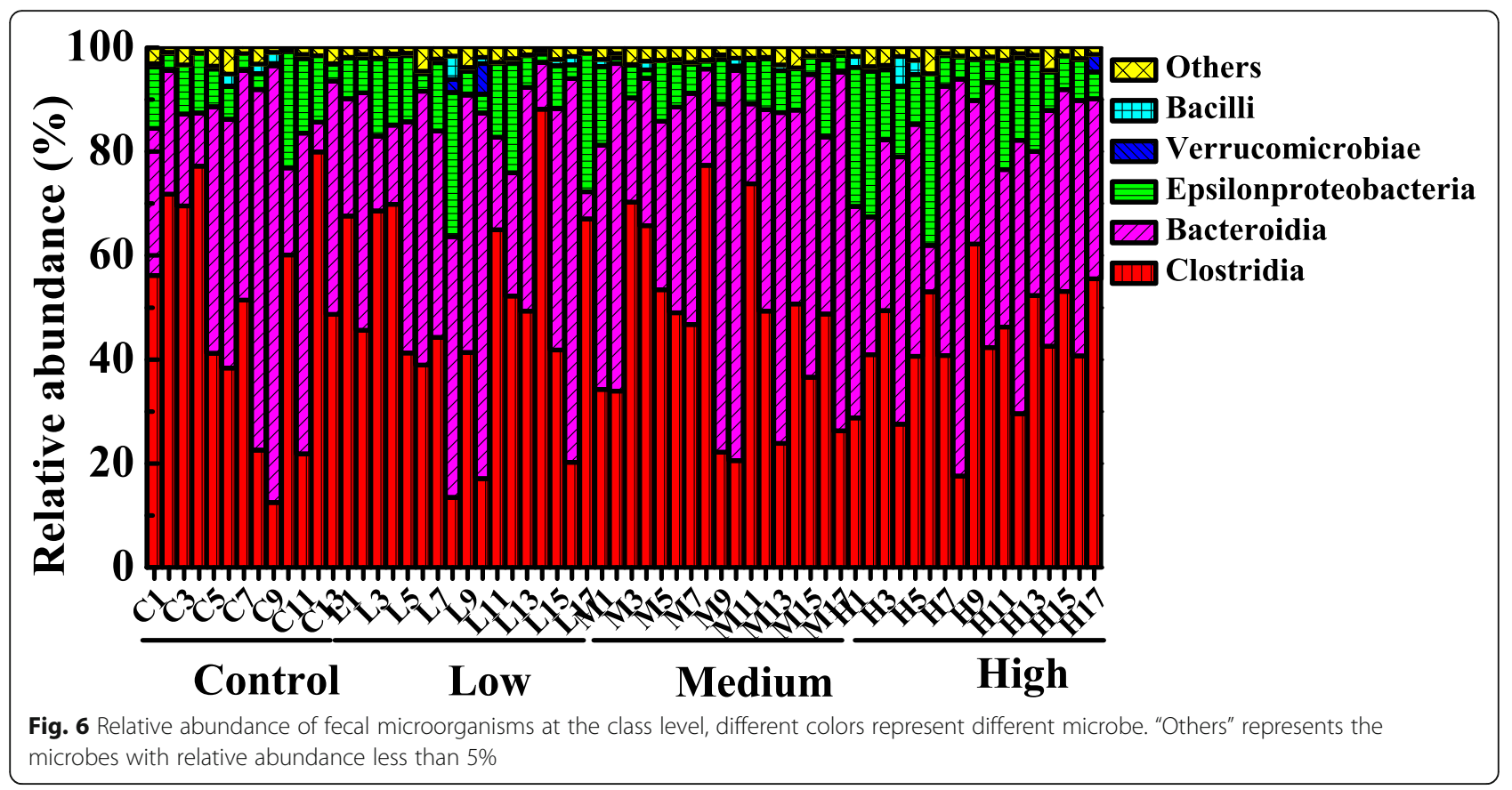

samples. The following genera were Bacteroides and Helicobacter (the average abundances were 13.96-20.80\% and $6.87-13.46 \%$, respectively) (Table. S5). Figure 13a showed that the proportions of Bacteroides were no statistical differences among the four groups. Helicobacter showed an increasing trend in relative abundances while there were no statistical differences (Fig. 13b). We could also get this information from heat map (Fig. S2). The relative abundances of Anaeroplasma (Fig. 13c; $P<0.001$ ) and Desulfovibrio (Fig. $13 \mathrm{~d} ; P<0.001$ ) were significantly different in various treatment groups. We observed an increase in the proportion of Desulfovibrio in $\mathrm{RbCl}$ treatment mice. The abundances of Alistipes (Fig. 13e; $P<0.01$ ) and Clostridium XlVa (Fig. 13f; $P<0.05$ ) were significantly higher in all the treatments than those of the control.

The LEfSe with default parameters was used to identify significant differences in relative abundances of fecal microbiota between the $\mathrm{RbCl}$ groups and control group. LEfSe analysis further confirmed enrichment microbes in different groups (Fig. 14a and b). The $\mathrm{RbCl}$ groups were significantly enriched for Deltaproteobacteria, Desulfovibrionales, Desulfovibrionaceae, Desulfovibrio, Rikenellaceae, Alistipes and
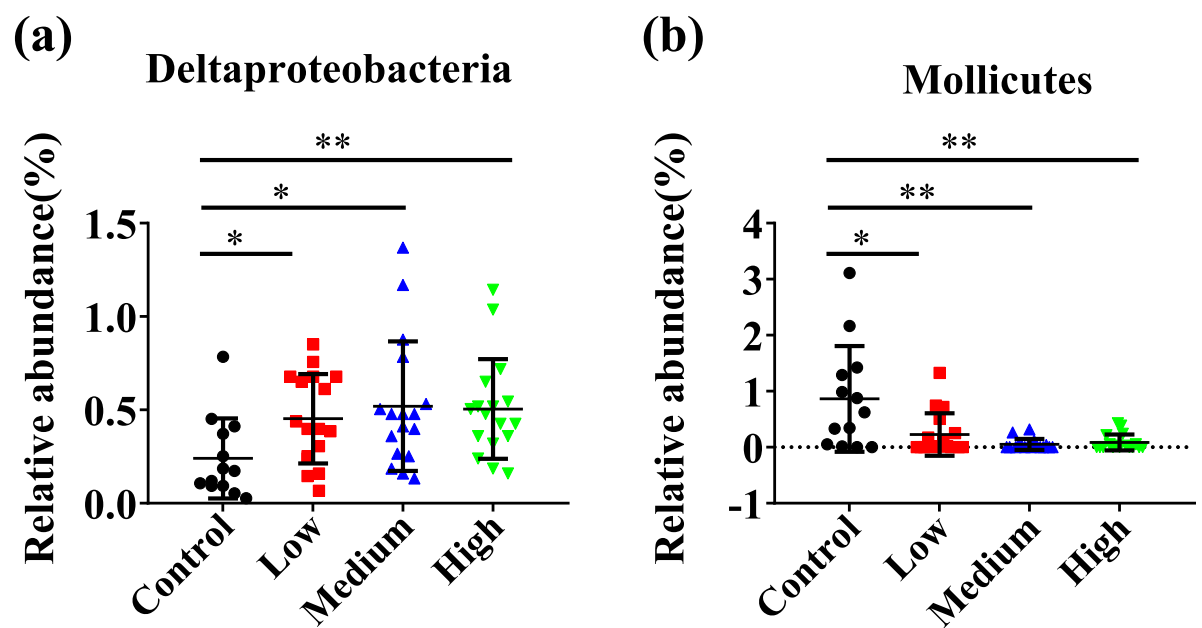

Fig. 7 Statistical analysis of relative abundance of fecal bacteria at the class level. a The abundances of Deltaproteobacteria were significantly increased in $\mathrm{RbCl}$ groups compared with the control group $(P<0.05)$. $\mathbf{b}$ The abundances of Mollicutes were significantly decreased in RbCl groups compared with the control group $(P<0.05)$. Data are shown as mean \pm SD. ${ }^{*} P<0.05,{ }^{* *} P<0.01,{ }^{* * *} P<0.001$ 


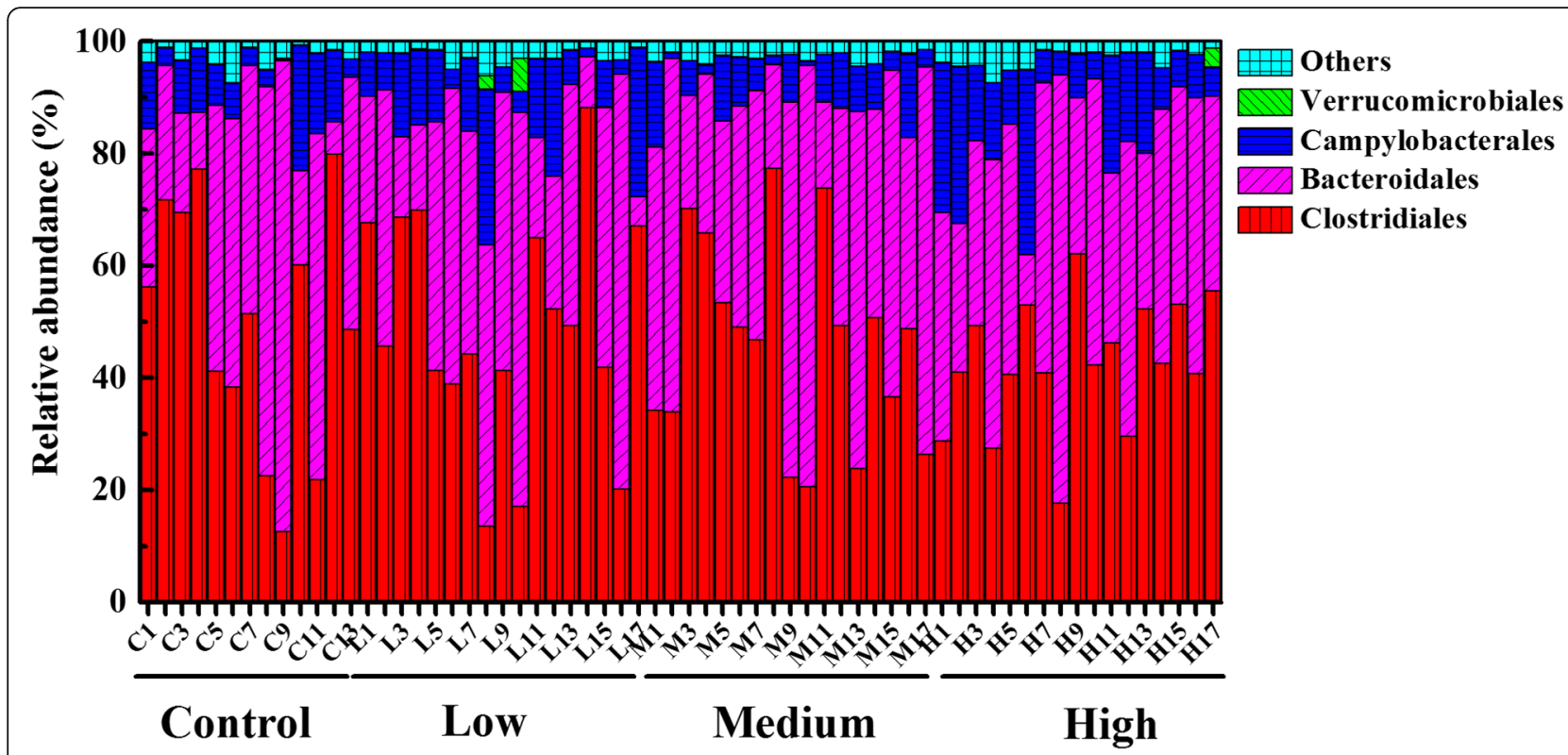

Fig. 8 Relative abundance of fecal microorganisms at the order level, different colors represent different microbe. "Others" represents the microbes with relative abundance less than $5 \%$

Clostridium XlVa. The control group was enriched for Tenericutes, Mollicutes, Anaeroplasmatales, Anaeroplasmataceae and Anaeroplasma.

\section{Effect of $\mathrm{RbCl}$ on fecal archaea composition}

We also analyzed the abundance of various archaea in fecal samples from each treatment group. At the phylum level, the fecal archaea from 4 groups were separated into Crenarchaeota and Euryarchaeota (Table. S1). The abundance of Crenarchaeota was higher in middle-dose group than control group (Fig. 15a), while the abundances of Euryarchaeota were not significantly different among the four groups (Fig. 15b).

The fecal archaea were separated into Thermoprotei and Thermoplasmata at the class level (Table. S2). The abundance of Thermoprotei increased in middle-dose group compared with the control group (Fig. S3a). The abundances of Thermoplasmata were not significantly different among the four groups (Fig. S3b).

The relative abundances of fecal archaea in control, low-dose, middle-dose and high-dose groups at the order level were shown in Table. S3. We observed an (a)

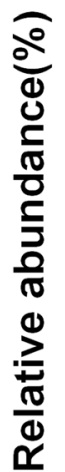

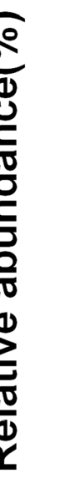

Anaeroplasmatales

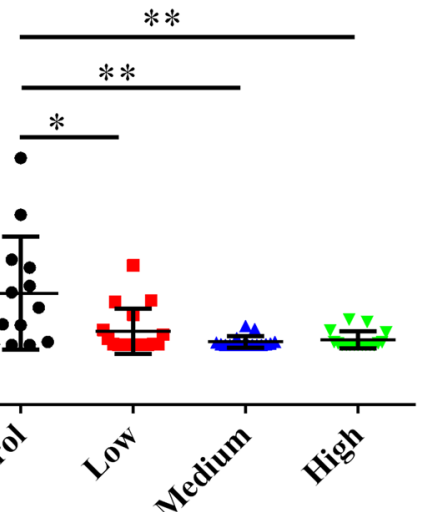

(b)

\section{Desulfovibrionales}

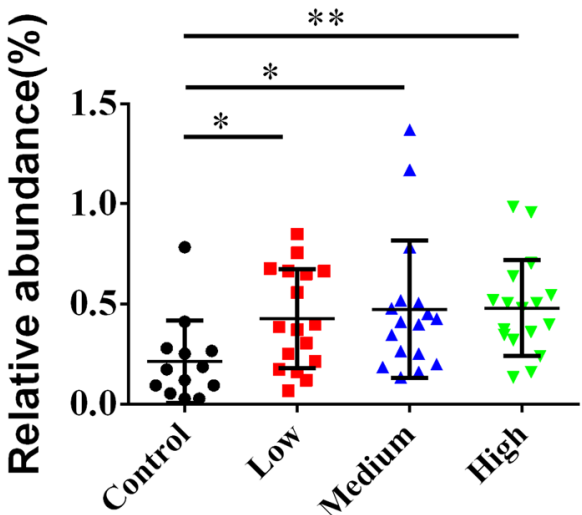

Fig. 9 Statistical analysis of relative abundance of fecal bacteria at the order level. a The abundances of Anaeroplasmatales were significantly decreased in $\mathrm{RbCl}$ groups compared with the control group $(P<0.05)$. $\mathbf{b}$ The abundances of Desulfovibrionales were significantly increased in RbCl groups compared with the control group $(P<0.05)$. Data are shown as mean \pm SD. ${ }^{*} P<0.05,{ }^{*} P<0.01,{ }^{* * *} P<0.001$ 


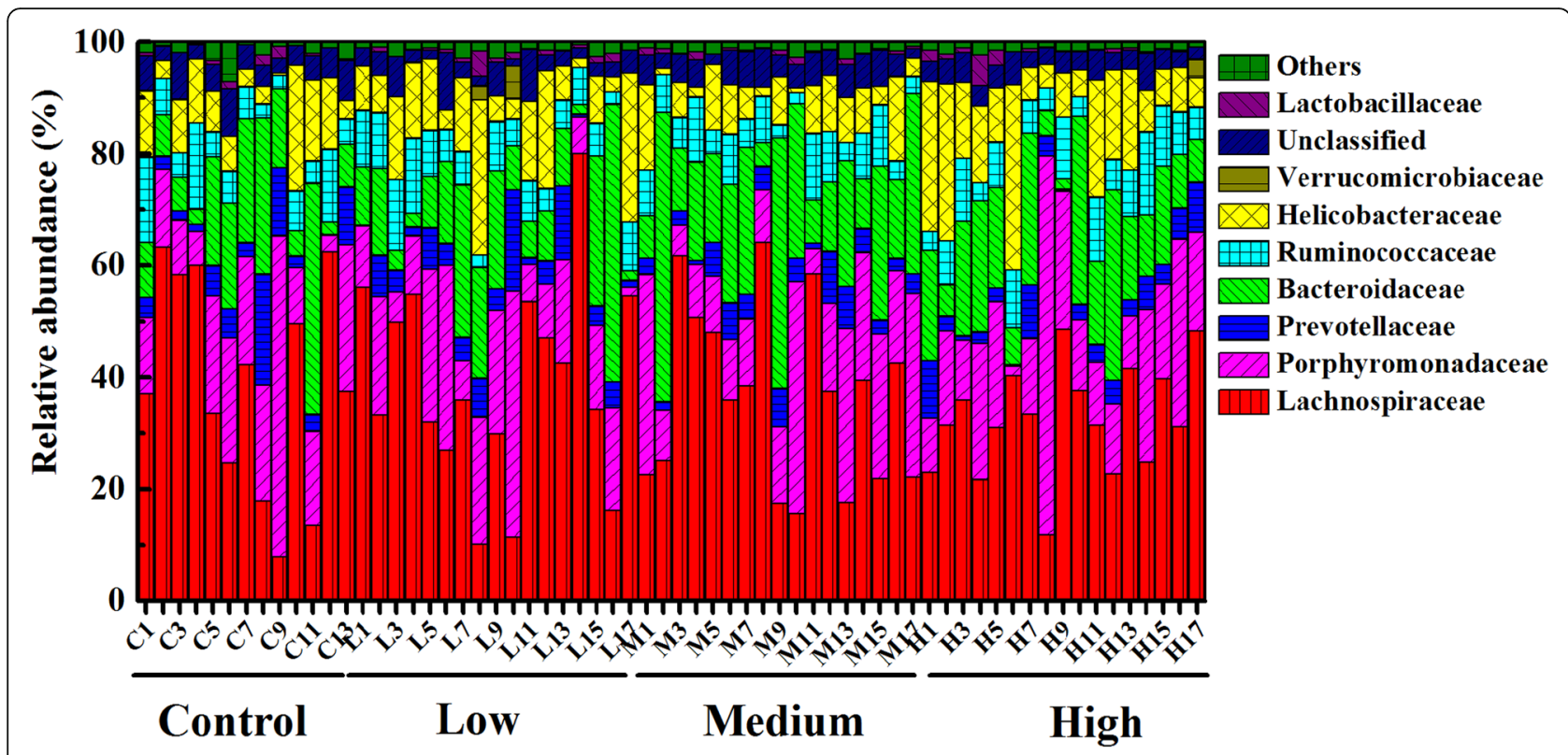

Fig. 10 Relative abundance of fecal microorganisms at the family level, different colors represent different microbe. "Others" represents the microbes with relative abundance less than $5 \%$

increase in the proportion of Sulfolobales in middle-dose group (Fig. S4a). The relative abundances of archaea Thermoplasmatales were not significantly different among four groups (Fig. S4b).

At the family level, Sulfolobaceae (the average abundances were $0-0.01 \%$ ) and Ferroplasmaceae (the average abundances were $0-0.01 \%$ ) were observed (Table. S4). The relative abundance of Sulfolobaceae increased in middle-dose group compared with the control group (Fig. S5a), while the abundances of Ferroplasmaceae demonstrated no statistical differences in control, lowdose, middle-dose and high-dose groups (Fig. S5b).

At the genus level, we observed two archaea Sulfolobus and Acidiplasma (Table. S5). Compared with the control group, the abundance of Sulfolobus increased in middledose group (Fig. S6a). The abundances of Acidiplasma were not significantly different among four groups (Fig. S6b).

Overall, the relative abundance of archaea in stool samples was very low. At the genus level, we only observed archaea Sulfolobus and Acidiplasma. Middle-dose $\mathrm{RbCl}$ could increase the relative abundance of Sulfolobus.

\section{Discussion}

This study found no differences in the alpha-richness and diversity indexes, which were consistent with some reports. Getachew et al. [24] reported no significant differences in bacterial diversity and species richness between saline and antidepressant drug ketamine groups. Furthermore, study by Zhang et al. [25] had compared the gut microbiota of T2DM rats and rats treated with metformin, with no significant differences reported in alpha-richness and diversity indices. It should be noted that the diversity of bacteria was affected by several factors, including health status, age, diet, medication and so on [26]. No difference in the alpha-richness and diversity may be explained in part by the consistency of age and diet among all samples. Part of the reasons may be that $\mathrm{RbCl}$ did not affect the diversity of the fecal microbial communities. In addition, we found that $\mathrm{RbCl}$ altered the structure of fecal bacterial communities, reflected in changes in fecal microbial composition. Wei et al. [27] observed that microbiota were significantly different between healthy rats and chronic diseased rats. Moreover, Zhang et al. [28] revealed that the microbiota structure changed significantly in response to high fat diet (HFD) feeding and berberine administration. Shifts of microbiota structure were also thought to occur in Crohn's disease patients [29]. Thus, changes in fecal microbial composition have played an important role in the progression of human diseases.

In our study, we observed that $\mathrm{RbCl}$ maintained the abundances of Firmicutes, Bacteroidetes, Actinobacteria, Bacteroides and Helicobacter. Chen et al. [30] reported that Firmicutes significantly reduced in intestinal lumen of CRC patients. In Crohn's disease, the abundance of Firmicutes was also significantly decreased [31, 32]. In addition, most works showed that Firmicutes was the higher abundant phylum in breast tissue [33-35]. In depression patients, it was also found that the relative abundance of Firmicutes significantly changed [36, 37], which was related to depression through inflammation [38]. Therefore, these findings indicated that changes of 
(a) Anaeroplasmataceae

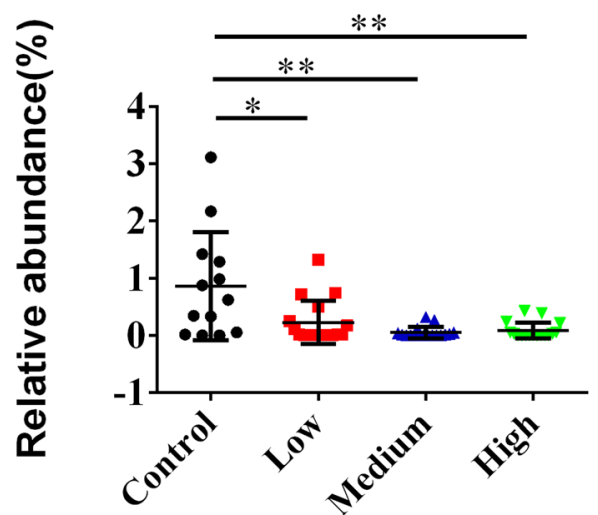

(c) Rikenellaceae

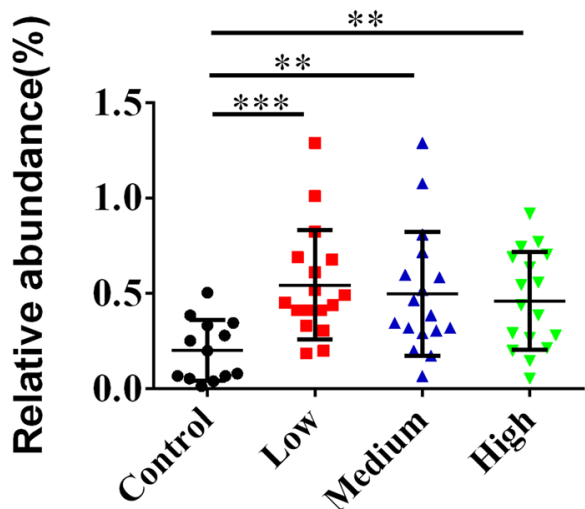

(b) Desulfovibrionaceae

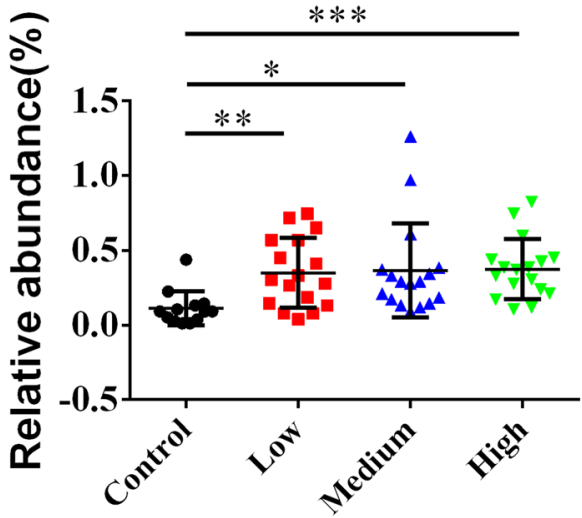

Fig. 11 Statistical analysis of relative abundance of fecal bacteria at the family level. a The abundances of Anaeroplasmataceae were significantly decreased in $\mathrm{RbCl}$ groups compared with the control group $(P<0.05)$. $\mathbf{b}$ The abundances of Desulfovibrionaceae were significantly increased in $\mathrm{RbCl}$ groups compared with the control group $(P<0.05)$. c The abundances of Rikenellaceae were significantly increased in $\mathrm{RbCl}$ groups compared with the control group $(P<0.05)$. Data are shown as mean \pm SD. ${ }^{*} P<0.05$, ${ }^{* *} P<0.01,{ }^{* * *} P<0.001$

Firmicutes were closely associated with diseases. Anticancer and anti-depressant effects of $\mathrm{RbCl}$ might be mediated by maintaining the abundance of Firmicutes in the gut. Bacteroidetes was non-endospore-forming anaerobes with bile resistance, accounting for more than $25 \%$ of gastrointestinal microbiota [39-41]. Proportions of Bacteroidetes were significantly lower in CRC rats than in healthy rats $[42,43]$. Although the exact physiological implications of Bacteroidetes in CRC were not fully understood, it was likely that inflammatory bowel diseases were known risk factors for $\mathrm{CRC}$, and a significant reduction of the phylum Bacteroidetes occurred in inflammatory bowel diseases [29, 44]. In addition, Jiang et al. [37] reported that Bacteroidetes were significantly more abundant in active-major depressive disorder subjects. The increase in Bacteroidetes was mainly promoted by Alistipes. Naseribafrouei et al. [45] reported increased abundance of Alistipes in the depressed subjects. Therefore, it can be inferred that changes of Bacteroidetes were closely associated with diseases. The Actinobacteria, which is comprised of gram-positive bacteria, includes 5 subclasses and 14 suborders [46]. Major depressive disorder (MDD) patients characterized by significant increase in the relative abundance of Actinobacteria [36]. Yang et al. [47] reported that the abundance of Actinobacteria was significantly higher in the depression mice. It was possible that enrichment of Actinobacteria was closely related to the development of depression. Exactly, $\mathrm{RbCl}$ did not significantly increase the abundances of Actinobacteria. Bacteroides is anaerobic, bile-resistant, non-spore-forming, gram-negative rods [48]. Changes of Bacteroides were assumed to be associated with metabolic diseases such as obesity and diabetes $[49,50]$. In Type I diabetes mellitus patients, Bacteroides was significantly increased [51]. The Bacteroides, which was known to be associated with increased gut permeability and inflammation, was positively associated with $\beta$-cell autoimmunity. Moreover, Zhu et al. [43] reported greater genera Bacteroides abundance in 


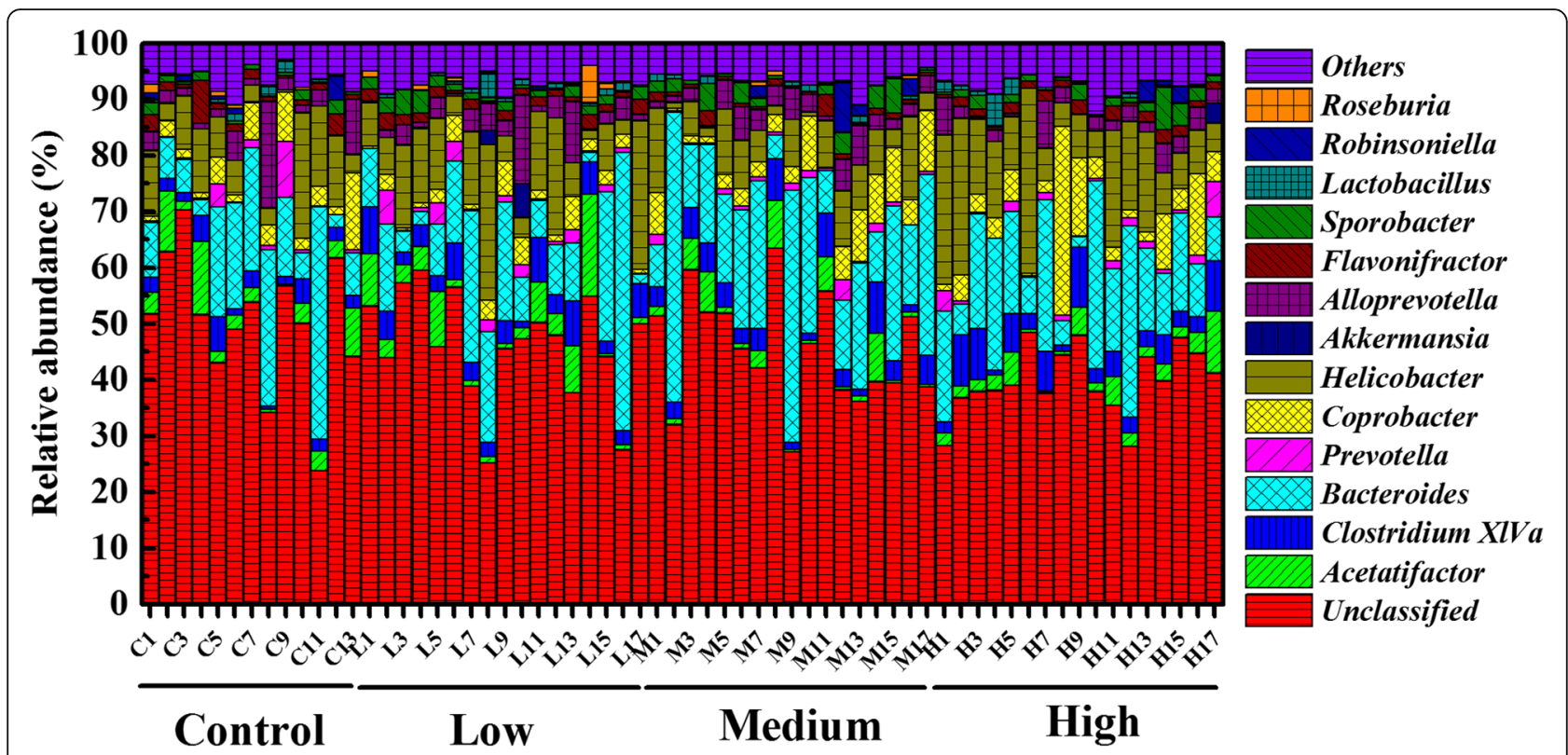

Fig. 12 Relative abundance of fecal microorganisms at the genus level, different colors represent different microbe. "Others" represents the microbes with relative abundance less than $5 \%$

colon cancer patients compared with controls. It was likely that Bacteroides produced a metalloprotease known as fragilysin, which might favor carcinogenesis. Taken together, these findings indicated that variations of Bacteroides were closely associated with diseases. It should be noted that $\mathrm{RbCl}$ did not change the proportion of Bacteroides. Lower abundance of Helicobacter was observed in gut microbiota of overall gastric cancer (GC) patients as compared to healthy controls [52]. It was possible that low proportion of Helicobacter contributed to the pathogenesis of GC. Exactly, $\mathrm{RbCl}$ did not change proportion of Helicobacter.

We also found $\mathrm{RbCl}$ significantly inhibited the abundances of Tenericutes, Mollicutes, Anaeroplasmatales, Anaeroplasmataceae and Anaeroplasma lineages. Yang et al. [47] reported that the abundance of Tenericutes significantly decreased in the depression mice. $\mathrm{RbCl}$ did not improve reduction of Tenericutes, which was consistent with reports. A previous animal study demonstrated that antidepressant drug (R)-ketamine and (S)ketamine also did not improve the reduced proportion of Tenericutes [47]. Additionally, Ketamine, known to induce antidepressant effects, also significantly reduced abundances of Tenericutes [24]. Tully et al. [53] reported that some species of Mollicutes were significant pathogens in human disease. A study also found that some Mollicutes were associated with diseases [54]. It was worth noting that the abundances of Mollicutes were significantly lower after treatment with $\mathrm{RbCl}$. The reduction of Mollicutes could decrease the pathogenesis of depression and cancers. However, one study has reported a significant reduction in the relative abundance of Mollicutes in MDD patients [47]. As the physiological mechanism of Mollicutes in depression was unclear, further studies on the relationship between depression and $\mathrm{Mol}$ licutes are needed. Anaeroplasmatales is an order of Mollicutes bacteria which do not have a cell wall [55]. Song et al. [56] found Anaeroplasmatales significantly increased in depression group. In addition, ketamine, known to induce antidepressant effects, significantly reduced the abundance of Anaeroplasmatales [24]. Exactly, the abundances of Anaeroplasmatales were significantly lower in $\mathrm{RbCl}$ groups. Anaeroplasmataceae, which belongs to Class Mollicutes and Order Anaeroplasmatales, is strictly anaerobic wall-less bacteria [57]. The abundance of Anaeroplasmataceae significantly increased in depression group [56]. Moreover, Anaeroplasmataceae significantly increased in patients with Crohn's disease localized in the colon (CCD), but significantly decreased in patients with ulcerative colitis (UC) [58]. Interestingly, we observed that $\mathrm{RbCl}$ inhibited the proportion of Anaeroplasmataceae. The reduction of Anaeroplasmataceae could decrease the pathogenesis of depression. In the study of colon cancer, Zeng et al. [59] found that the abundance of Anaeroplasma increased in the HFD-azoxymethane (AOM) group. The Anaeroplasma is a gram-negative bacterium, which belongs to Mollicutes class, Tenericutes phylum. Anaeroplasma was opportunistic pathogens which elicited various host immune responses in numerous human diseases including colon cancer $[60,61]$. Interestingly, the results of $\mathrm{RbCl}$ inhibited the proportion of the bacteria. 
(a)

(c)

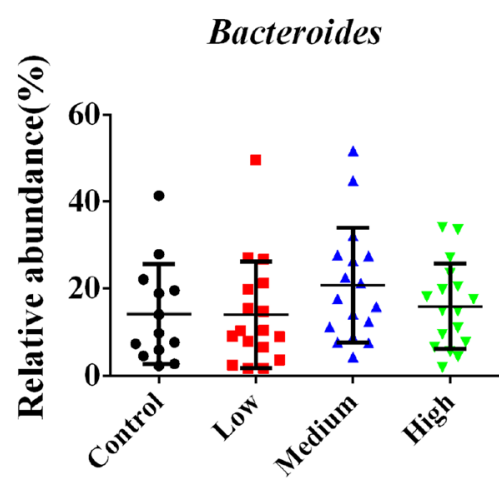

Anaeroplasma

(e)

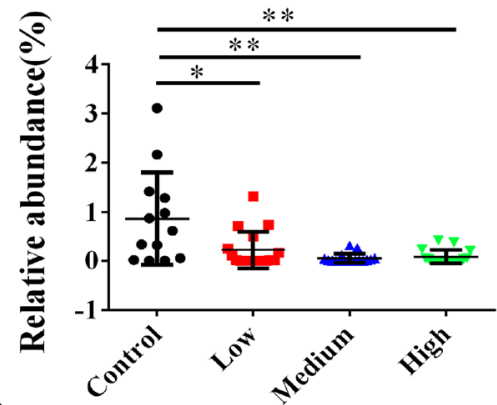

Alistipes

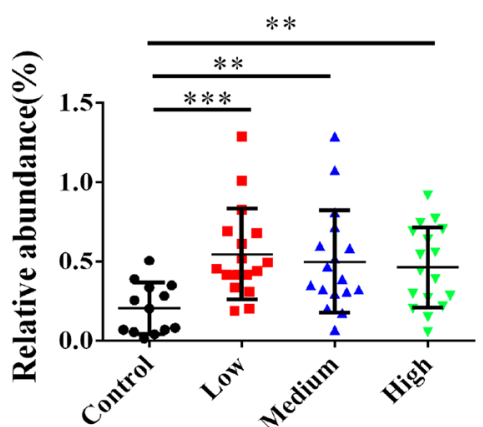

(b)

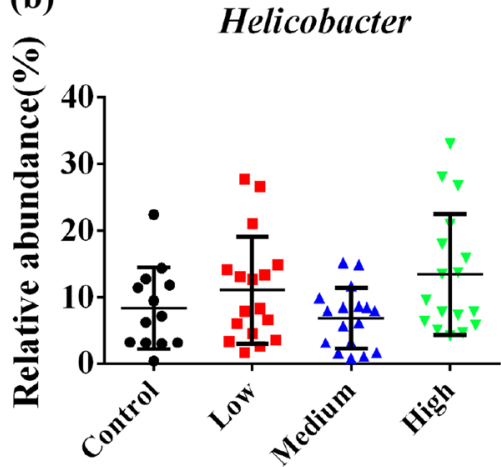

(d)

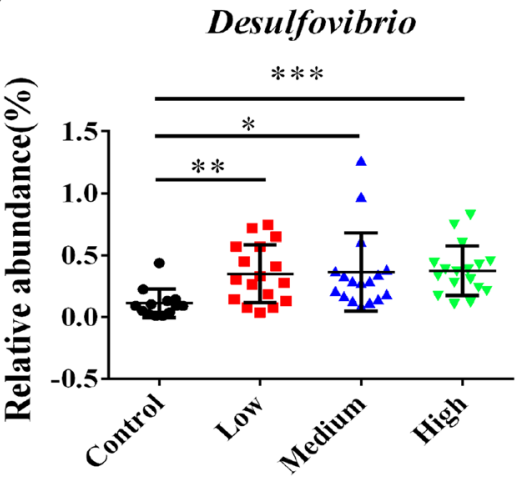

(f)

\section{Clostridium XIVa}

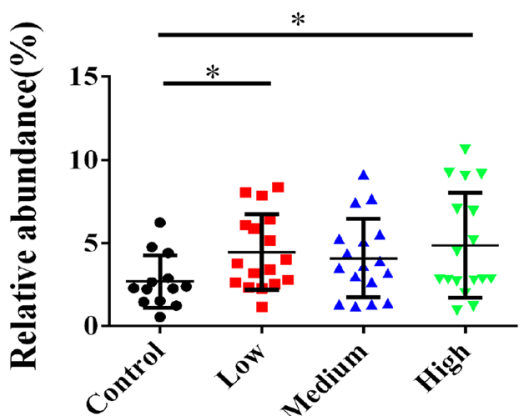

Fig. 13 Statistical analysis of relative abundance of fecal bacteria at the genus level. a The abundances of Bacteroides were not significantly altered among four groups. b The abundances of Helicobacter showed no statistical differences among four groups. c The abundances of Anaeroplasma were significantly decreased in $\mathrm{RbCl}$ groups compared with the control group. $\mathbf{d}$ The abundances of Desulfovibrio showed statistical differences in $\mathrm{RbCl}$ groups compared with the control group. e The abundances of Alistipes significantly increased in $\mathrm{RbCl}$ groups compared with the control group. $\mathbf{f}$ The abundances of Clostridium XIVa were significantly higher in RbCl groups than those of the control. Data are shown as mean $\pm \mathrm{SD}$. ${ }^{*} P<0.05,{ }^{* *} P<0.01,{ }^{* * *} P<0.001$

Expressions of sulfate-reducing bacteria (SRB) including Deltaproteobacteria, Desulfovibrionales, Desulfovibrionaceae and Desulfovibrio were significantly higher in $\mathrm{RbCl}$ groups than control group. Deltaproteobacteria belonging to Proteobacteria is sulfate-reducing bacteria [62]. Hydrogen sulfide $\left(\mathrm{H}_{2} \mathrm{~S}\right)$ produced by SRB was a product of sulfate reduction [63]. $\mathrm{H}_{2} \mathrm{~S}$ could lead to chronic inflammation and imbalance between cellular proliferation, apoptosis and differentiation by damaging the intestinal epithelium [64]. Reports showed that
Deltaproteobacteria was possibly associated with CRC [65, 66]. Jin et al. [67] reported that Deltaproteobacteria was commonly pathogenic bacteria in the intestine. Desulfovibrionales, belonging to Deltaproteobacteria, is also a sulfate-reducing bacteria that can reduce sulfur to produce hydrogen sulfide $\left(\mathrm{H}_{2} \mathrm{~S}\right)$ [62]. Desulfovibrionaceae, which was the main biological source of hydrogen sulfate $\left(\mathrm{H}_{2} \mathrm{~S}\right)$, involved in a wide range of physiological processes by influencing cellular signaling pathways and sulfhydration of target proteins $[68,69]$. Zhang et al. 


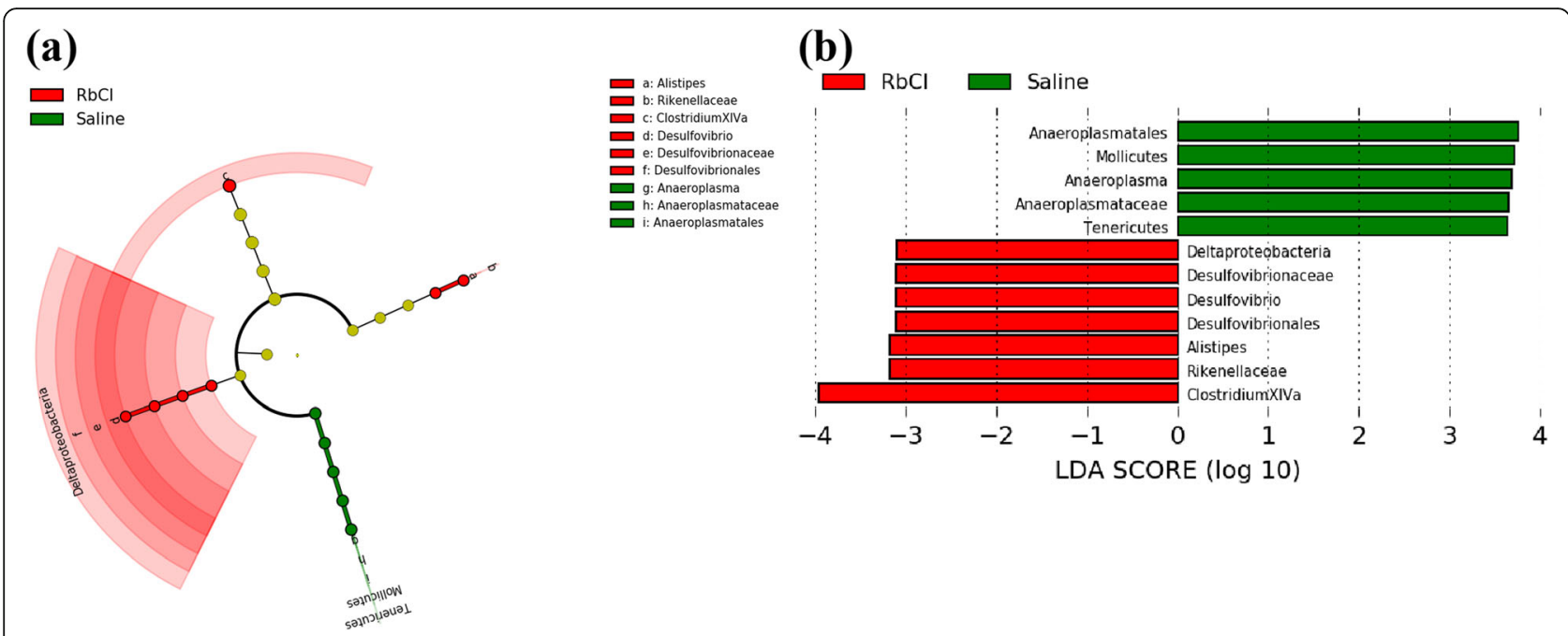

Fig. 14 LEfSe analysis of enriched bacterial taxa in fecal microbiota between RbCl groups and the control group. a Taxonomic representation of statistically and biologically consistent differences between $\mathrm{RbCl}$ and control mice. Significant differences were represented by different colors (red and green represented the enriched microbes in the $\mathrm{RbCl}$ and Saline treatment groups, respectively). $\mathbf{b}$ Histogram of the LDA scores for differentially abundant genera between the two treatment groups

[70] reported that the proportion of Desulfovibrionaceae increased in animal models of metabolic syndrome. Desulfovibrio could also produce $\mathrm{H}_{2} \mathrm{~S}$ by reducing sulfate [71]. $\mathrm{H}_{2} \mathrm{~S}$ derived from Desulfovibrio was associated with gastrointestinal disorders, such as UC, Crohn's disease, and irritable bowel syndrome [68]. Besides, Hale et al. [72] also reported that Desulfovibrio produced metabolites such as secondary bile acids, which may catalyze the formation of colorectal cancer. However, it should be noted that the proportions of sulfate-reducing bacteria were promoted by $\mathrm{RbCl}$. $\mathrm{RbCl}$ led to the enrichment of sulfate-reducing bacteria which could cause inflammation directly or indirectly in mice. It was likely that $\mathrm{RbCl}$ used as antigen in healthy mice which could elicit immune responses.

In addition, $\mathrm{RbCl}$ significantly increased the abundances of Rikenellaceae, Alistipes and Clostridium XlVa. $\mathrm{Wu}$ et al. [73] found that the abundance Rikenellaceae decreased in the colitis-associated colorectal cancer (CAC) group compared with control group. Alkadhi et al. [74] also reported that the proportion of Rikenellaceae reduced in CAC mice. In addition, the report found that Rikenellaceae was overrepresented in healthy control subjects [36]. Following $\mathrm{RbCl}$ treatment, the abundance of Rikenellaceae increased in the present study. Therefore, the increase in Rikenellaceae abundance could accelerate

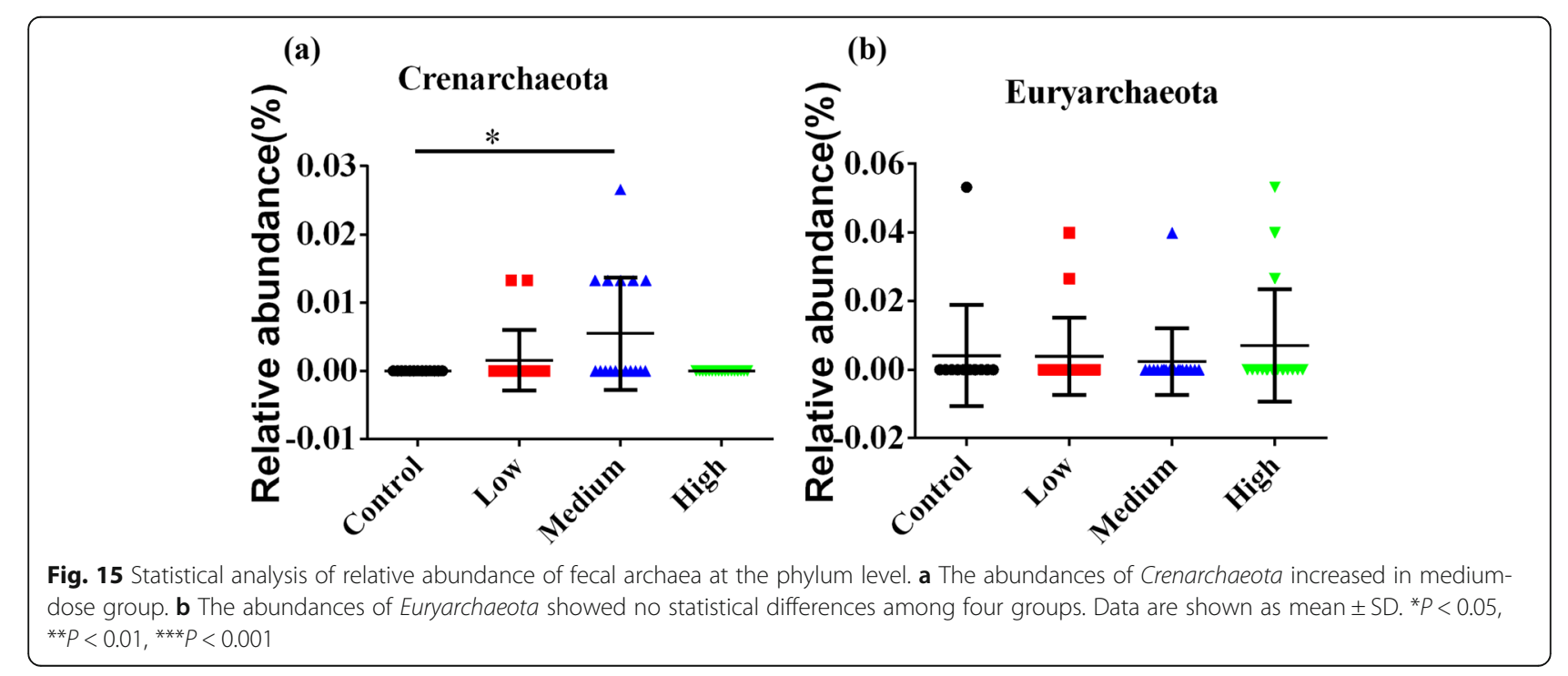


the antitumor efficacy of $\mathrm{RbCl}$. Alistipes, which belongs to Bacteroidetes, is present in the human intestinal tract [75]. Alistipes was indole-positive and may thus influence tryptophan availability [76]. In our results, $\mathrm{RbCl}$ promoted the abundance of Alistipes. As tryptophan was also the precursor of serotonin, enrichment of Alistipes might affect serotonergic system by interfering with tryptophan metabolism. Clostridium XlVa, belonging to Firmicutes phylum, produces short-chain fatty acids (SCFAs) [77]. The SCFAs produced in the gut are mainly acetate, butyrate and propionate [78]. SCFAs could modulate cell functions either by inhibiting histone deacetylase activity, or through the activation of 'metabolite-sensing' G-protein coupled receptors (GPCRs) such as GPR43 and protect the integrity of epithelial barrier [79-81]. $\mathrm{RbCl}$ promoted the abundance of Clostridium XlVa. The increase in abundance Clostridium XlVa could alleviate the pathogenesis of depression and cancers. Clostridium XlVa was significantly lower in CRC patients than healthy subjects [77]. Clostridium XIVa was overrepresented in healthy control subjects [36, 82].

Regarding the composition of archaea, the abundances of Crenarchaeota, Thermoprotei, Sulfolobales, Sulfolobaceae and Sulfolobus lineages increased in middle-dose $\mathrm{RbCl}$ groups. Crenarchaeota was originally considered to grow in habitats characterized by high temperature, high salinity, or an extreme $\mathrm{pH}$. Later studies found that $\mathrm{Cre}$ narchaeota also seem to occur ubiquitously in temperate or cold aquatic [83] and terrestrial environments [84]. The presence of Crenarchaeota in intestinal tracts was reported by Friedrich et al. [85]. In addition, Rieu-Lesme et al. [86] suggested that Crenarchaeota was present in the microbiota of the human digestive ecosystem. Thermoprotei, the crenarchaeal class, consists solely of obligate thermophiles. Thermophiles were well-known for participating in rampant lateral gene transfer (LGT) $[87,88]$. It was likely that the nature of their extreme environments encouraged the exchange of genetic material. Thermoprotei mostly occurred in the marine environment [89]. However, report showed that Thermoprotei was observed to have an appreciably higher representation in healthy child [90]. Interestingly, the proportion of Thermoprotei was promoted by middle-dose $\mathrm{RbCl}$ in this study. Sulfolobales, a monophyletic group within the Crenarchaeota, is thermophilic sulfur-metabolizing archaea [91]. The report found that Sulfolobales was present in human feces sample [86]. The family Sulfolobaceae is composed of extreme thermoacidophiles that are found in terrestrial environments [92]. The Sulfolobaceae could produce bacteriocin, which played an important role in microbial interaction or microbeenvironment interactions, and therefore improved their adaptation in extreme environments [93]. Enrichment of Sulfolobaceae promoted by middle-dose $\mathrm{RbCl}$ may be beneficial in combating disease-related adverse environments. The genera Sulfolobus, which belongs to Sulfologaceae, grows at low $\mathrm{pH}(2-3)$ and high temperature $\left(70-85^{\circ} \mathrm{C}\right)[94,95]$. The acidophilic and thermophilic properties of Sulfolobus offered many obvious advantages for industrial applications [96, 97]. In addition, Sulfolobus was able to reduce ferric iron when growing on elemental sulfur as an energy source [98].

Furthermore, $\mathrm{RbCl}$ maintained the abundances of archaea Euryarchaeota, Thermoplasmata, Thermoplasmatales, Ferroplasmaceae, Acidiplasma lineages. Euryarchaeota, one of the four major divisions of archaea, contributed substantially to global energy cycling [99]. Euryarchaeota was detected in marine picoplankton $[100,101]$ and in coastal salt marsh and continental shelf sediments [102]. Methanobrevibacter smithii, which belonged to Euryarchaeota phylum, was a major archaeal player in human gut system [103]. A few studies confirmed that $M$. smithii was probably involved in inflammatory bowel disease (or Crohn's disease), irritable bowel syndrome, colorectal cancer, and obesity [104, 105]. Methanobrevibacter oralis, belonging to Euryarchaeota phylum, was the predominating methanogenic species in the oral cavity [103]. M. oralis was identified in apical periodontitis [106]. Therefore, these findings proved that Euryarchaeota might play key roles for human health and disease. However, the proportions of Euryarchaeota did not significantly change after $\mathrm{RbCl}$ treatment. Thermoplasmata was affiliated with Euryarchaeota phylum. Auguet et al. [107] showed that Thermoplasmata represented important component of soil microbial communities. In the human body, Li et al. [108] found that Thermoplasmata was not the predominant archaeons in the subgingival dental plaque and Thermoplasmata was closely correlated with chronic periodontitis. Following $\mathrm{RbCl}$ treatment, the abundance of Thermoplasmata did not significantly change. Horz et al. [109] found that Thermoplasmatales existed in the human oral cavity. He et al. [110] reported that Thermoplasmatales was also observed in healthy subjects, but the abundance of Thermoplasmatales increased in individuals with periodontitis. It was possible that enrichment of Thermoplasmatales contributed to the pathogenesis of periodontitis. Exactly, $\mathrm{RbCl}$ did not improve the enrichment of Thermoplasmatales. The Ferroplasmaceae is represented by cell wall-deficient, acidophilic, facultatively anaerobic and iron-oxidizing archaea [111]. As iron oxidizers, the family Ferroplasmaceae may contribute to the cycle of iron and sulfur [112]. It was likely that Ferroplasmaceae was involved in the pathogenesis of diseases through oxidizing iron. Thus, further studies on the relationships between diseases and Ferroplasmaceae are needed. Interestingly, $\mathrm{RbCl}$ did not significantly change the abundance of Ferroplasmaceae. Acidiplasma, which belongs to the family Ferroplasmaceae, order Thermoplasmatales, phylum Euryarchaeota, is a novel acidophilic, cell-wall-less archaeon 
[113]. The genera Acidiplasma included two species, namely Acidiplasma aeolicum and Acidiplasma cupricumulans [112]. Acidiplasma aeolicum and Acidiplasma cupricumulans were isolated from the hydrothermal pool located on Vulcano Island (Italy) and chalcocite/coppercontaining heaps (Myanmar), respectively [113]. It should also be noted that there were no reports on the relationships between Acidiplasma and diseases. In our results, Acidiplasma was observed in stool samples and its abundances were not significantly changed by $\mathrm{RbCl}$.

Some reports found $\mathrm{Rb}$ could be used as anticancer and anti-depressant drugs. The mechanisms of $\mathrm{Rb}$ against cancer and neurological disease remain unclear. Microbiota may participate in the pathogenesis of depression through the brain-gut-microbiota axis [114]. Serotonin $(5-\mathrm{HT})$ is a critical signaling molecule in the brain-gut-microbiota axis [115]. The accumulation of 5$\mathrm{HT}$ and the rate of synthesis of 5-HT in the brain were enhanced by intraperitoneal administration of $\mathrm{RbCl}$ [116]. In the present study, Clostridium XlVa, SCFAs producing bacteria, was significantly promoted by $\mathrm{RbCl}$. SCFAs could promote colonic 5-HT production [117, 118]. Enrichment of Alistipes promoted by $\mathrm{RbCl}$ might disrupt the intestinal serotonergic system by affecting tryptophan metabolism. Therefore, the microbes might partly promote the anticancer and anti-depressant effects of $\mathrm{RbCl}$ via brain-gut-microbiota axis.

\section{Conclusions}

In summary, our results revealed $\mathrm{RbCl}$ significantly altered fecal microbial composition. $\mathrm{RbCl}$ maintained the abundances of dominant bacteria. However, $\mathrm{RbCl}$ significantly altered the abundances of less richness microbes. Changes in fecal microbes might in part contribute to the anticancer or anti-depressant effects of $\mathrm{RbCl}$. Clearly, further functional analysis of the role of specific fecal microorganisms and their interactions with brain-gutmicrobiota axis is expected.

\section{Methods}

\section{Experimental animals and experimental design}

Three-week old male Swiss mice used as experimental animals (license number SCXK (Xiang) 2016-0002) were purchased and raised in the Laboratory Animal Science Department (LASD) of Central South University with Specific Pathogen Free (SPF) level environment. The living environment of the mice was of constant temperature $\left(20 \pm 2{ }^{\circ} \mathrm{C}\right)$, constant humidity $(50 \pm 10 \%)$, and free access to water and food. Mice were strictly controlled in normal biological rhythms and the light and dark environments were $12 \mathrm{~h}$, respectively. All animal experiments in this study were approved by the Animal Breeding and Committee of the Department of Laboratory Animal Science of Central South University and were strictly evaluated in accordance with the Regulations on Animal Management of Central South University. The mice were kept in the LASD for a week without any treatment to adapt to the environment. Sixty-four mice were randomly assigned into four groups: one was blank control group which was intervened with normal saline $(n=13)$, and the other three groups were divided into low-dose $(n=17)$, middle-dose $(n=17)$, and high-dose group $(n=17)$ according to the different $\mathrm{RbCl}$ dosage $(20 \mathrm{mg} / \mathrm{L}(0.17 \mathrm{mmol} / \mathrm{L}), 50 \mathrm{mg} / \mathrm{L}$ $(0.41 \mathrm{mmol} / \mathrm{L}), 100 \mathrm{mg} / \mathrm{L}(0.83 \mathrm{mmol} / \mathrm{L})$, respectively $)$. Five or four mice were randomly placed in each mouse cage. The mice of the above experimental groups were intragastrically administered of $\mathrm{RbCl}$ in $0.2 \mathrm{~mL}$ twice per day for 6 consecutive weeks. During this period, the mice were weighed weekly.

\section{Fecal samples collection and properties analysis}

After 6 weeks of drug treatments, the mice to be sampled were placed on a clean ultra-clean bench with sterile filter papers for taking stool samples. The fecal samples were collected into the sterile tubes immediately after defecation. The tubes were marked and snap frozen in liquid nitrogen. All mice were sacrificed by pentobarbital overdose $(60 \mathrm{mg} / \mathrm{kg})$ in the ultra-clean workbench. The kidneys, heart, lungs, pancreatic, spleen, stomach and liver were rapidly excised from mouse and weighed.

\section{Fecal DNA extraction and sequencing}

Each fecal sample (approximately $0.2 \mathrm{~g}$ ) was used for total gut microbiome DNA extraction with QIAGEN QIAamp kit. Extractions were performed according to specific operating instructions. The extracted total genomic DNA was detected by agarose gel electrophoresis and qualified DNA samples were used in subsequent experiments. PCR amplification and library preparation were performed using 515 F (5'-GTGCCAGCMGCC GCGGTAA-3') and 806R (5'-GGACTACHVGGG TWTCTAAT-3') primers to target the V4 region of the $16 \mathrm{~S}$ rRNA gene. The PCR products for each sample were subjected to electrophoresis at a voltage of $100 \mathrm{~V}$ for about $1 \mathrm{~h}$ using a $2 \%$ agarose gel. The target band was recovered by tapping under UV light, and E.Z.N.A.TM Gel Purification Kit (OMEGA Bio-Tek Inc., USA) was used for product purification. The purified product was quantified using a Nanodrop spectrophotometer (ND-1000 spectrophotometer, Wilmington, USA). Illumina MiSeq (Illumina, San Diego, CA) sequencing required the library constructed from the mixture of $200 \mathrm{ng}$ of each purified product.

\section{Data processing and sequence analysis}

The MiSeq sequencing data were analyzed using the Galaxy pipeline developed by Prof. Zhou's lab (http:// 
zhoulab5.rccc.ou.edu/) at University of Oklahoma. The resulting sequences were further filtered based on quality score and sequence length. To merge the paired-end reads into full-length amplicon sequence, the FLASH software tool was used based on overlapping bases. The sequences were clustered into operational taxonomic units (OTU) at or above 97\% identity. According to previous reports, OTUs reaching $97 \%$ similarity were used to analyze alpha diversity (Shannon and Simpson), and richness (Ace, Chao and Sobs) $[119,120]$.

\section{Statistical analysis}

IBM SPSS Statistics 19.0 software was used for statistical analysis. Since comparison was performed between two groups (saline and low, middle, high, respectively), Student T-test was applied for detecting significant differences in specific measured parameters. All values were expressed as the mean \pm standard deviation (SD). Probability values of less than 0.05 were considered to show a statistical significance. Microbiota community diversity and richness were analyzed using vegan package and R software (version 3.5.1). LEFSe (Linear discriminant analysis effect size), CPCoA (constrained principal coordinate analysis) and Heatmap plot were performed on ehbio BioPharm platform (http://www. ehbio.com).

\section{Supplementary Information}

The online version contains supplementary material available at https://doi. org/10.1186/s12866-021-02095-4.

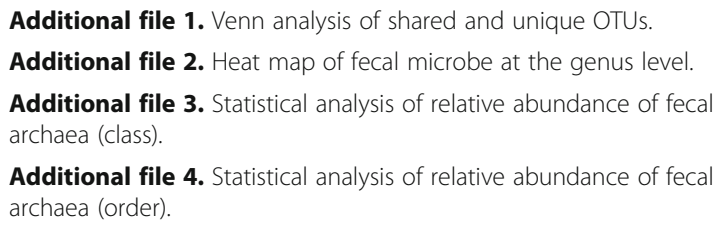

Additional file 5. Statistical analysis of relative abundance of fecal archaea (family)

Additional file $\mathbf{6}$. Statistical analysis of relative abundance of fecal archaea (genus).

Additional file 7. Relative abundances of all microorganisms at the phylum level.

Additional file 8. Relative abundances of all microorganisms at the class level.

Additional file 9. Relative abundances of all microorganisms at the order level.

Additional file 10. Relative abundances of all microorganisms at the family level.

Additional file 11. Relative abundances of all microorganisms at the genus level.

\section{Abbreviations}

Rb: rubidium; RbCl: Rubidium chloride; CPCOA: Constrained principal coordinate analysis; HFD: High fat diet; CRC: Colorectal cancer; MDD: Major depressive disorder; GC: Gastric cancer; CCD: Crohn's disease localized in the colon; UC: Ulcerative colitis; AOM: Azoxymethane; SRB: Sulfate-reducing bacteria; $\mathrm{H}_{2} \mathrm{~S}$ : Hydrogen sulfide; CAC: Colitis-associated colorectal cancer; SCFAs: Short-chain fatty acids; GPCRs: G-protein coupled receptors;

LGT: Lateral gene transfer; 5-HT: Serotonin; LASD: Laboratory Animal Science Department; SPF: Specific Pathogen Free; OUT: Operational taxonomic units; LEFSe: Linear discriminant analysis effect size; ANOVA: One-way analyses of variance

\section{Acknowledgements}

Not applicable.

\section{Authors' contributions}

Conceptualization, H.Z. and Z.H.; methodology, Q.C. and Y.Z.; formal analysis, Q.C. and S.L.; investigation, Q.C.; resources, Z.H. and H.Z.; data curation, Q.C.; writing-original draft preparation, Q.C. and W.Y.; writing-review and editing, L.H. and H.Z. All authors have read and approved the manuscript.

\section{Funding}

This work financially supported by the National Natural Science Foundation of China (Project No. 51774339) and Fundamental Research Funds for the Central Universities of Central South University (1053320184188). The funders had no role in the design of the study, collection, analysis, and interpretation of data or preparation of the manuscript.

\section{Availability of data and materials}

All sequence data were deposited into the NCBI Sequence Read Archive database (accession No. PRJNA630020). All the 16S rDNA sequences of 64 samples have been upload to NCBI database (SRA accession No.

SRR11671062 - SRR11671125).

\section{Ethics approval and consent to participate}

All experiments were approved by the Animal Breeding and Committee of the Department of Laboratory Animal Science of Central South University and were strictly evaluated in accordance with the Regulations on Animal Management of Central South University.

\section{Consent for publication}

Not applicable.

\section{Competing interests}

The authors declare that they have no competing interests.

\section{Author details}

${ }^{1}$ School of Life Sciences, Central South University, Changsha 410013, China ${ }^{2}$ School of Minerals Processing and Bioengineering, Key Laboratory of Biohydrometallurgy of Ministry of Education, Central South University, Changsha 410083, China.

Received: 7 May 2020 Accepted: 19 January 2021

Published online: 15 February 2021

\section{References}

1. Anke M, Angelow L. Rubidium in the food chain. Fresenius J Anal Chem. 1995;352(1):236-9. https://doi.org/10.1007/BF00322334.

2. Lombeck I, Kasperek K, Feinendegen LE, Bremer HJ. Rubidium-a possible essential trace element : 1 . The rubidium content of whole blood of healthy and dietetically treated children. Biol Trace Elem Res. 1980;2(3):193-8. https://doi.org/10.1007/BF02785354

3. Cheng $X$, Zhou YC, Zhou B, Huang YC, Wang GZ, Zhou GB. Systematic analysis of concentrations of 52 elements in tumor and counterpart normal tissues of patients with non-small cell lung cancer. Cancer Med. 2019;8(18): 7720-7. https://doi.org/10.1002/cam4.2629.

4. Garg AN, Singh V, Weginwar RG, Sagdeo VN. An elemental correlation study in cancerous and normal breast tissue with successive clinical stages by neutron activation analysis. Biol Trace Elem Res. 1994;46(3):185-202. https://doi.org/10.1007/BF02789296.

5. Stolk JM, Conner RL, Barchas JD. Rubidium-induced increase in shockelicited aggression in rats. Psychopharmacologia. 1971;22(3):250-60. https://doi.org/10.1007/bf00401787

6. Rahimi N, Hassanipour M, Yarmohammadi F, Faghir-Ghanesefat $H$, Pourshadi $\mathrm{N}$, Bahramnejad E, et al. Nitric oxide and glutamate are contributors of anti- 
seizure activity of rubidium chloride: A comparison with lithium. Neurosci Lett. 2019;708:134349. https://doi.org/10.1016/j.neulet.2019.134349.

7. Kordjazy N, Haj-Mirzaian A, Amiri S, Ostadhadi S, Kordjazy M, Sharifzadeh M, Dehpour AR. Elevated level of nitric oxide mediates the anti-depressant effect of rubidium chloride in mice. Eur J Pharmacol. 2015;762:411-8. https://doi.org/10.1016/j.ejphar.2015.06.030.

8. Rouf MS. Clinical Association Between Alterations of Boron, Cesium, Rhenium and Rubidium with the Pathogenesis of Atherosclerosis. Am J Clin Exp Med. 2015;3(5):247-54. https://doi.org/10.11648/j.ajcem.20150305.19.

9. Tamburo E, Varrica D, Dongarrà G, Grimaldi LM. Trace elements in scalp hair samples from patients with relapsing-remitting multiple sclerosis. PLoS One. 2015;10(4):e0122142-e55. https://doi.org/10.1371/journal.pone.0122142.

10. Tamano $\mathrm{H}$, Enomoto S, Oku N, Takeda A. Preferential uptake of zinc manganese, and rubidium in rat brain tumor. Nucl Med Biol. 2002;29(4): 505-508; doi: https://doi.org/10.1016/S0969-8051(02)00289-5.

11. Meltzer HL, Taylor RM, Platman SR, Fieve RR. Rubidium: a potential modifier of affect and behaviour. Nature. 1969;223(5203):321-2. https://doi.org/10. 1038/223321a0.

12. Paschalis $C$, Jenner FA, Lee CR. Effects of rubidium chloride on the course of manic-depressive illness. J R Soc Med. 1978;71(5):343-52.

13. Nguyen TT, Kosciolek T, Eyler LT, Knight R, Jeste DV. Overview and systematic review of studies of microbiome in schizophrenia and bipolar disorder. J Psychiat Res. 2018;99:50-61. https://doi.org/10.1016/j.jpsychires. 2018.01.013.

14. Cho M, Carter J, Harari S, Pei Z. The interrelationships of the gut microbiome and inflammation in colorectal carcinogenesis. Clin Lab Med. 2014;34(4):699-710. https://doi.org/10.1016/j.cll.2014.08.002.

15. Singh RK, Chang HW, Yan D, Lee KM, Ucmak D, Wong K, Abrouk M, Farahnik B, Nakamura M, Zhu TH, et al. Influence of diet on the gut microbiome and implications for human health. J Transl Med. 2017;15(1): 73-89. https://doi.org/10.1186/s12967-017-1175-y.

16. Petrov VA, Saltykova IV, Zhukova IA, Zhukova NG, Dorofeeva YB, Tyakht AV, Altukhov IA, Kostryukova ES, Titova MA, Mironova YS, et al. Comparison study of gut microbiota in case of Parkinson's disease and other neurological disorders. Bull Siberian Med. 2016;15(5):113-25.

17. Tremlett H, Bauer KC, Appel-Cresswell S, Finlay BB, Waubant E. The gut microbiome in human neurological disease: a review. Ann Neurol. 2017; 81(3):369-82. https://doi.org/10.1002/ana.24901.

18. Konkel $\mathrm{L}$. The environment within: exploring the role of the gut microbiome in health and disease. Environ Health Perspect. 2013;121(9): A276-A81. https://doi.org/10.1289/ehp.121-A276.

19. Yu J, Feng Q, Wong SH, Zhang D, Liang QY, Qin Y, Tang L, Zhao H, Stenvang J, Li Y, et al. Metagenomic analysis of faecal microbiome as a tool towards targeted non-invasive biomarkers for colorectal cancer. Gut. 2017; 66(1):70-8. https://doi.org/10.1136/gutjnl-2015-309800.

20. Arkan MC. The intricate connection between diet, microbiota, and cancer: a jigsaw puzzle. Semin Immunol. 2017;32:35-42. https://doi.org/10.1016/j. smim.2017.08.009.

21. Chen JJ, Zheng P, Liu YY, Zhong XG, Wang HY, Guo YJ, Xie P. Sex differences in gut microbiota in patients with major depressive disorder. Neuropsychiatr Dis Treat. 2018;14:647-655. doi: https://doi.org/10.2147/NDT. S159322. PMID: 29520144; PMCID: PMC5833751.

22. Messaoudi M, Violle N, Bisson JF, Desor D, Javelot $H$, Rougeot $C$. Beneficial psychological effects of a probiotic formulation (Lactobacillus helveticus R0052 and Bifidobacterium longum R0175) in healthy human volunteers. Gut Microbes. 2011;2(4):256-61. https://doi.org/10.4161/gmic. 2.4.16108.

23. Messaoudi M, Lalonde R, Violle N, Javelot H, Desor D, Nejdi A, Bisson JF, Rougeot C, Pichelin M, Cazaubiel M, et al. Assessment of psychotropic-like properties of a probiotic formulation (Lactobacillus helveticus R0052 and Bifidobacterium longum R0175) in rats and human subjects. Br J Nutr. 2011; 105(5):755-64. https://doi.org/10.1017/s0007114510004319.

24. Getachew B, Aubee Jl, Schottenfeld RS, Csoka AB, Thompson KM, Tizabi Y. Ketamine interactions with gut-microbiota in rats: relevance to its antidepressant and anti-inflammatory properties. BMC Microbiol. 2018;18(1): 222-31. https://doi.org/10.1186/s12866-018-1373-7.

25. Zhang C, Ma S, Wu J, Luo L, Qiao S, Li R, Xu W, Wang N, Zhao B, Zhang Y, et al. A specific gut microbiota and metabolomic profiles shifts related to antidiabetic action: The similar and complementary antidiabetic properties of type 3 resistant starch from Canna edulis and metformin. Pharmacol Res. 2020;159:104985. https://doi.org/10.1016/j.phrs.2020.104985.
26. Lozupone CA, Stombaugh Jl, Gordon Jl, Jansson JK, Knight R. Diversity, stability and resilience of the human gut microbiota. Nature. 2012;489(7415): 220-30. https://doi.org/10.1038/nature11550.

27. Wei H, Dong L, Wang T, Zhang M, Hua W, Zhang C, Pang X, Chen M, Su M, Qiu Y, et al. Structural shifts of gut microbiota as surrogate endpoints for monitoring host health changes induced by carcinogen exposure. FEMS Microbiol Ecol. 2010;73(3):577-86. https://doi.org/10.1111/j.1574-6941.2010. 00924.x.

28. Zhang X, Zhao Y, Zhang M, Pang X, Xu J, Kang C, Li M, Zhang C, Zhang Z, $\mathrm{Li} X$, et al. Structural changes of gut microbiota during berberine-mediated prevention of obesity and insulin resistance in high-fat diet-fed rats. PLOS One. 2012;7(8):e42529-e40. https://doi.org/10.1371/journal.pone.0042529.

29. Frank DN, St. Amand AL, Feldman RA, Boedeker EC, Harpaz N, Pace NR. Molecular-phylogenetic characterization of microbial community imbalances in human inflammatory bowel diseases. Proc Natl Acad Sci U S A. 2007;104(34):13780-5. https://doi.org/10.1073/pnas.0706625104.

30. Chen W, Liu F, Ling Z, Tong X, Xiang C. Human intestinal lumen and mucosa-associated microbiota in patients with colorectal cancer. PLoS One. 2012;7(6):e39743-e51. https://doi.org/10.1371/journal.pone.0039743.

31. Kaakoush NO, Day AS, Huinao KD, Leach ST, Lemberg DA, Dowd SE, Mitchell HM. Microbial dysbiosis in pediatric patients with Crohn's disease. J Clin Microbiol. 2012;50(10):3258-66. https://doi.org/10.1128/JCM.01396-12.

32. Gophna U, Sommerfeld K, Gophna S, Doolittle WF, van Zanten SJO V. Differences between tissue-associated intestinal microfloras of patients with Crohn's disease and ulcerative colitis. J Clin Microbiol. 2006;44(11):4136-41. https://doi.org/10.1128/JCM.01004-06

33. Fernandez MF, Reina-Perez I, Astorga JM, Rodriguez-Carrillo A, Plaza-Diaz J, Fontana L. Breast Cancer and its relationship with the microbiota. Int J Environ Res Public Health. 2018;15(8):1747-66. https://doi.org/10.3390/ ijerph15081747.

34. Urbaniak C, Gloor GB, Brackstone M, Scott L, Tangney M, Reid G. The microbiota of breast tissue and its association with breast Cancer. Appl Environ Microb. 2016;82(16):5039-48. https://doi.org/10.1128/AEM.01235-16.

35. Urbaniak C, Cummins J, Brackstone M, Macklaim JM, Gloor GB, Baban CK, Scott L, Burton JP, Francis KP, Tangney M, et al. Microbiota of human breast tissue. Appl Environ Microb. 2014;80(10):3007-14. https://doi.org/10.1128/ AEM.00242-14.

36. Zheng P, Zeng B, Zhou C, Liu M, Fang Z, Xu X, Zeng L, Chen J, Fan S, Du X, et al. Gut microbiome remodeling induces depressive-like behaviors through a pathway mediated by the host's metabolism. Mol Psychiatry. 2016;21(6):786-96. https://doi.org/10.1038/mp.2016.44.

37. Jiang $H$, Ling $Z$, Zhang $Y$, Mao H, Ma Z, Yin Y, Wang W, Tang W, Tan Z, Shi J, et al. Altered fecal microbiota composition in patients with major depressive disorder. Brain Behav Immun. 2015;48:186-94. https://doi.org/10. 1016/j.bbi.2015.03.016.

38. de La Serre CB, Ellis CL, Lee J, Hartman AL, Rutledge JC, Raybould HE. Propensity to high-fat diet-induced obesity in rats is associated with changes in the gut microbiota and gut inflammation. Am J Physiol-Gastr L. 2010;299(2):G440-G8. https://doi.org/10.1152/ajpgi.00098.2010.

39. Wilson $\mathrm{KH}$, Blitchington RB. Human colonic biota studied by ribosomal DNA sequence analysis. Appl Environ Microb. 1996;62(7):2273-8.

40. Franks AH, Harmsen HJM, Raangs GC, Jansen GJ, Schut F, Welling GW. Variations of bacterial populations in human feces measured by fluorescent in situ hybridization with group-specific 165 rRNA-targeted oligonucleotide probes. Appl Environ Microb. 1998;64(9):3336-45.

41. Kenneth HW, Ikeda JS, Rhonda BB. Phylogenetic placement of community members of human colonic biota. Clin Infect Dis. 1997:25:S114-S6.

42. Wang T, Cai G, Qiu Y, Fei N, Zhang M, Pang X, Jia W, Cai S, Zhao L. Structural segregation of gut microbiota between colorectal cancer patients and healthy volunteers. ISME J. 2012;6(2):320-9. https://doi.org/10.1038/ ismej.2011.109.

43. Zhu Q, Jin Z, Wu W, Gao R, Guo B, Gao Z, Yang Y, Qin H. Analysis of the intestinal lumen microbiota in an animal model of colorectal cancer. PLoS One. 2014;9(6):e90849-e58. https://doi.org/10.1371/journal. pone.0090849.

44. Ott SJ, Musfeldt M, Wenderoth DF, Hampe J, Brant O, Fölsch UR, Timmis KN, Schreiber S. Reduction in diversity of the colonic mucosa associated bacterial microflora in patients with active inflammatory bowel disease. Gut. 2004;53(5):685-93. https://doi.org/10.1136/gut.2003.025403.

45. Naseribafrouei A, Hestad K, Avershina E, Sekelja M, Linløkken A, Wilson R, Rudi K. Correlation between the human fecal microbiota and depression. 
Neurogastroenterol Motil. 2014;26(8):1155-62. https://doi.org/10.1111/ nmo.12378.

46. Marco Ventura CC, Tauch A, Chandra G, Fitzgerald GF, Chater KF, van Sinderen D. Genomics of Actinobacteria: tracing the evolutionary history of an ancient phylum. Microbiol Mol Biol Rev. 2007;71(3):495-548. https://doi. org/10.1128/MMBR.00005-07.

47. Yang C, Qu Y, Fujita Y, Ren Q, Ma M, Dong C, Hashimoto K. Possible role of the gut microbiota-brain axis in the antidepressant effects of (R)-ketamine in a social defeat stress model. Transl Psychiatry. 2017;7(12):1294-304. https://doi.org/10.1038/s41398-017-0031-4.

48. Wexler HM. Bacteroides: the good, the bad, and the Nitty-gritty. Clin Microbiol Rev. 2007;20(4):593-621. https://doi.org/10.1128/CMR.00008-07.

49. Bervoets L, Van Hoorenbeeck K, Kortleven I, Van Noten C, Hens N, Vael C, Goossens $\mathrm{H}$, Desager KN, Vankerckhoven V. Differences in gut microbiota composition between obese and lean children: a cross-sectional study. Gut Pathog. 2013;5(1):10-9. https://doi.org/10.1186/1757-4749-5-10.

50. Zhang X, Shen D, Fang Z, Jie Z, Qiu X, Zhang C, Chen Y, Ji L. Human gut microbiota changes reveal the progression of glucose intolerance. PLoS One. 2013;8(8):e71108-e18. https://doi.org/10.1371/journal.pone.0071108,

51. Bibbò $\mathrm{S}$, Dore MP, Pes GM, Delitala G, Delitala AP. Is there a role for gut microbiota in type 1 diabetes pathogenesis? Ann Med. 2017:49(1):11-22. https://doi.org/10.1080/07853890.2016.1222449.

52. Liang $W$, Yang $Y$, Wang $H$, Wang $H$, Yu X, Lu Y, Shen S, Teng L. Gut microbiota shifts in patients with gastric cancer in perioperative period. Medicine. 2019;98(35):e16626-e35. https://doi.org/10.1097/MD. 0000000000016626.

53. Tully JG. Current status of the Mollicute Flora of humans. Clin Infect Dis. 1993;17:S2-9.

54. Brown JS. Correlation of mollicutes and their viruses with multiple sclerosis and other demyelinating diseases. Med Hypotheses. 2003;60(2):298-303. https://doi.org/10.1016/s0306-9877(02)00390-0.

55. Zhao Y, Davis R, Wei W, Lee I-M. Should 'Candidatus Phytoplasma' be retained within the order Acholeplasmatales? Int J Syst Evol Microbiol. 2015; 65(3):1075-82. https://doi.org/10.1099/ijs.0.000050.

56. Song J, Ma W, Gu X, Zhao L, Jiang J, Xu Y, Zhang L, Zhou M, Yang L. Metabolomic signatures and microbial community profiling of depressive rat model induced by adrenocorticotrophic hormone. J Transl Med. 2019; 17(1):224-35. https://doi.org/10.1186/s12967-019-1970-8.

57. Petzel JP, McElwain MC, DeSantis D, Manolukas J, Williams MV, Hartman PA, Allison MJ, Pollack JD. Enzymic activities of carbohydrate, purine, and pyrimidine metabolism in the Anaeroplasmataceae (class Mollicutes). Arch Microbiol. 1989;152(4):309-16. https://doi.org/10.1007/BF00425166.

58. Willing BP, Dicksved J, Halfvarson J, Andersson AF, Lucio M, Zheng Z, Järnerot G, Tysk C, Jansson JK, Engstrand L. A Pyrosequencing Study in Twins Shows That Gastrointestinal Microbial Profiles Vary With Inflammatory Bowel Disease Phenotypes. Gastroenterology. 2010;139(6):1844-1854.e1; doi: https://doi.org/10.1053/j.gastro.2010.08.049.

59. Zeng H, Ishaq SL, Liu Z, Bukowski MR. Colonic aberrant crypt formation accompanies an increase of opportunistic pathogenic bacteria in C57BL/6 mice fed a high-fat diet. J Nutr Biochem. 2018;54:18-27. https//doi.org/10.1016/j.jnutbio.2017.11.001.

60. Yang C, Chalasani G, Ng Y-H, Robbins PD. Exosomes released from mycoplasma infected tumor cells activate inhibitory B cells. PLoS One. 2012; 7(4):e36138-e50. https://doi.org/10.1371/journal.pone.0036138.

61. Xu Y, Li H, Chen W, Yao X, Xing Y, Wang X, Zhang J, Meng G. Mycoplasma hyorhinis activates the NLRP3 inflammasome and promotes migration and invasion of gastric cancer cells. PLoS One. 2013;8(11):e77955-e68. https:// doi.org/10.1371/journal.pone.0077955.

62. Yu YN, Fang JY. Gut microbiota and colorectal Cancer. Gastrointest Tumors. 2015;2(1):26-32. https://doi.org/10.1159/000380892.

63. Chen L, Brar MS, Leung FCC, Hsiao WLW. Triterpenoid herbal saponins enhance beneficial bacteria, decrease sulfate-reducing bacteria, modulate inflammatory intestinal microenvironment and exert cancer preventive effects in ApcMin/+ mice. Oncotarget. 2016;7(21):31226-42. https://doi.org/10.18632/oncotarget.8886.

64. Deplancke B, Gaskins HR. Hydrogen sulfide induces serum-independent cell cycle entry in nontransformed rat intestinal epithelial cells. FASEB J. 2003; 17(10):1310-2. https://doi.org/10.1096/fj.02-0883fje.

65. Carbonero F, Benefiel AC, Gaskins HR. Contributions of the microbial hydrogen economy to colonic homeostasis. Nat Rev Gastroenterol Hepatol. 2012;9(9):504-18. https://doi.org/10.1038/nrgastro.2012.85.

66. Medani M, Collins D, Docherty NG, Baird AW, O'Connell PR, Winter DC Emerging role of hydrogen sulfide in colonic physiology and pathophysiology. Inflamm Bowel Dis. 2010;17(7):1620-5. https://doi.org/10 1002/ibd.21528.

67. Jin C, Zeng Z, Fu Z, Jin Y. Oral imazalil exposure induces gut microbiota dysbiosis and colonic inflammation in mice. Chemosphere. 2016;160:34958. https://doi.org/10.1016/j.chemosphere.2016.06.105.

68. Singh SB, Lin HC. Hydrogen sulfide in physiology and diseases of the digestive tract. Microorganisms. 2015;3(4):866-889; doi: https://doi.org/10. 3390/microorganisms3040866.

69. Sen N. Functional and Molecular Insights of Hydrogen Sulfide Signaling and Protein Sulfhydration. J Mol Biol. 2017;429(4):543-61. https://doi.org/10. 1016/j.jmb.2016.12.015

70. Zhang C, Zhang M, Wang S, Han R, Cao Y, Hua W, Mao Y, Zhang X, Pang X, Wei $C$, et al. Interactions between gut microbiota, host genetics and diet relevant to development of metabolic syndromes in mice. ISME J. 2010;4(2): 232-41. https://doi.org/10.1038/ismej.2009.112.

71. Muyzer G, Stams AJM. The ecology and biotechnology of sulphate-reducing bacteria. Nat Rev Microbiol. 2008;6(6):441-54. https://doi.org/10.1038/ nrmicro1892.

72. Hale VL, Chen J, Johnson S, Harrington SC, Yab TC, Smyrk TC, Nelson H, Boardman LA, Druliner BR, Levin TR, et al. Shifts in the fecal microbiota associated with adenomatous polyps. Cancer Epidemiol Biomark Prev. 2017; 26(1):85-94. https://doi.org/10.1158/1055-9965.Epi-16-0337.

73. Wu M, Wu Y, Deng B, Li J, Cao H, Qu Y, Qian X, Zhong G. Isoliquiritigenin decreases the incidence of colitis-associated colorectal cancer by modulating the intestinal microbiota. Oncotarget. 2016;7(51):85318-31. https://doi.org/10.18632/oncotarget.13347.

74. Alkadhi S, Kunde D, Cheluvappa R, Randall-Demllo S, Eri R. The murine appendiceal microbiome is altered in spontaneous colitis and its pathological progression. Gut Pathog. 2014;6(1):25-34. https://doi.org/10. 1186/1757-4749-6-25.

75. Tyrrell KL, Warren YA, Citron DM, Goldstein EJC. Re-assessment of phenotypic identifications of Bacteroides putredinis to Alistipes species using molecular methods. Anaerobe. 2011;17(3):130-4. https://doi.org/10. 1016/j.anaerobe.2011.04.002.

76. Song Y, Könönen E, Rautio M, Liu C, Bryk A, Eerola E, Finegold SM. Alistipes onderdonkii sp. nov. and Alistipes shahii sp. nov., of human origin. Int J Syst Evol Microbiol. 2006;56(8):1985-90. https://doi.org/10.1099/ijs.0.64318-0.

77. Li L, Li X, Zhong W, Yang M, Xu M, Sun Y, Ma J, Liu T, Song X, Dong W, et al. Gut microbiota from colorectal cancer patients enhances the progression of intestinal adenoma in Apcmin/+ mice. EBioMedicine. 2019; 48:301-15. https://doi.org/10.1016/j.ebiom.2019.09.021.

78. Tan J, McKenzie C, Potamitis M, Thorburn A, Mackay C, Macia L. The role of short-chain fatty acids in health and disease. Adv Immunol. 2014;121:91119. https://doi.org/10.1016/B978-0-12-800100-4.00003-9.

79. Maslowski KM, Vieira AT, Ng A, Kranich J, Sierro F, Di Y, Schilter HC, Rolph MS, Mackay F, Artis D, et al. Regulation of inflammatory responses by gut microbiota and chemoattractant receptor GPR43. Nature. 2009;461(7268): 1282-6. https://doi.org/10.1038/nature08530.

80. Fukuda S, Toh H, Hase K, Oshima K, Nakanishi Y, Yoshimura K, Tobe T, Clarke $J M$, Topping DL, Suzuki T, et al. Bifidobacteria can protect from enteropathogenic infection through production of acetate. Nature. 2011; 469(7331):543-7. https://doi.org/10.1038/nature09646.

81. Macia L, Tan J, Vieira AT, Leach K, Stanley D, Luong S, Maruya M, McKenzie Cl, Hijikata A, Wong C, et al. Metabolite-sensing receptors GPR43 and GPR109A facilitate dietary fibre-induced gut homeostasis through regulation of the inflammasome. Nat Commun. 2015;6(1):6734-48. https://doi.org/10. 1038/ncomms7734.

82. Vaughn BP, Kaiser T, Staley C, Hamilton MJ, Reich J, Graiziger C, Singroy S, Kabage AJ, Sadowsky MJ, Khoruts A. A pilot study of fecal bile acid and microbiota profiles in inflammatory bowel disease and primary sclerosing cholangitis. Clin Exp Gastroenterol. 2019;12:9-19. https://doi.org/10.2147/ CEG.S186097.

83. Karner MB, DeLong EF, Karl DM. Archaeal dominance in the mesopelagic zone of the Pacific Ocean. Nature. 2001;409(6819):507-10. https://doi.org/10. 1038/35054051.

84. DeLong EF. Everything in moderation: Archaea as 'non-extremophiles'. Curr Opin Genet Dev. 1998;8(6):649-654; doi: https://doi.org/10.1016/S0959437X(98)80032-4.

85. Friedrich MW, Schmitt-Wagner D, Lueders T, Brune A. Axial differences in community structure of Crenarchaeota and Euryarchaeota in the highly compartmentalized gut of the soil-feeding termite Cubitermes 
orthognathus. Appl Environ Microbiol. 2001;67(10):4880-90. https://doi.org/ 10.1128/aem.67.10.4880-4890.2001.

86. Rieu-Lesme F, Delbès C, Sollelis L. Recovery of partial $16 \mathrm{~S}$ rDNA sequences suggests the presence of Crenarchaeota in the human digestive ecosystem. Curr Microbiol. 2005;51(5):317-21. https://doi.org/ 10.1007/s00284-005-0036-8.

87. Nelson KE, Clayton RA, Gill SR, Gwinn ML, Dodson RJ, Haft DH, Hickey EK, Peterson JD, Nelson WC, Ketchum KA, et al. Evidence for lateral gene transfer between Archaea and Bacteria from genome sequence of Thermotoga maritima. Nature. 1999;399(6734):323-9. https://doi.org/10. 1038/20601.

88. Aravind L, Tatusov RL, Wolf YI, Walker DR, Koonin EV. Evidence for massive gene exchange between archaeal and bacterial hyperthermophiles. Trends Genet. 1998;14(11):442-4. https://doi.org/10.1016/S0168-9525(98)01553-4.

89. Huson DH, Richter DC, Mitra S, Auch AF, Schuster SC. Methods for comparative metagenomics. BMC Bioinform. 2009;10(1):S12-21. https://doi. org/10.1186/1471-2105-10-S1-S12.

90. Gupta SS, Mohammed MH, Ghosh TS, Kanungo S, Nair GB, Mande SS. Metagenome of the gut of a malnourished child. Gut Pathog. 2011;3(1):715. https://doi.org/10.1186/1757-4749-3-7.

91. Segerer AH, Trincone A, Gahrtz M, Stetter KO. Stygiolobus azoricus gen. nov. , sp. nov. Represents a Novel Genus of Anaerobic, Extremely Thermoacidophilic Archaebacteria of the Order Sulfolobales. Int J Syst Bacteriol. 1991;41(4):495-501. https://doi.org/10.1099/00207713-41-4-495.

92. Counts JA, Vitko NP, Kelly RM. Complete genome sequences of extremely Thermoacidophilic metal-mobilizing type strain members of the Archaeal family Sulfolobaceae, Acidianus brierleyi DSM-1651, Acidianus sulfidivorans DSM-18786, and Metallosphaera hakonensis DSM-7519. Microbiol Resour Announc. 2018;7(2):e00831-18. https://doi. org/10.1128/MRA.00831-18.

93. Wang S, Zheng Z, Zou H, Li N, Wu M. Characterization of the secondary metabolite biosynthetic gene clusters in archaea. Comput Biol Chem. 2019; 78:165-9. https://doi.org/10.1016/j.compbiolchem.2018.11.019.

94. Brock TD, Brock KM, Belly RT, Weiss RL. Sulfolobus: a new genus of sulfuroxidizing bacteria living at low pH and high temperature. Arch Mikrobiol. 1972;84(1):54-68. https://doi.org/10.1007/BF00408082.

95. Schocke L, Brasen C, Siebers B. Thermoacidophilic Sulfolobus species as source for extremozymes and as novel archaeal platform organisms. Curr Opin Biotechnol. 2019;59:71-7. https://doi.org/10.1016/j.copbio.2019.02.012.

96. Turner P, Mamo G, Karlsson EN. Potential and utilization of thermophiles and thermostable enzymes in biorefining. Microb Cell Factories. 2007;6(1):931. https://doi.org/10.1186/1475-2859-6-9.

97. Hess M. Thermoacidophilic proteins for biofuel production. Trends Microbiol. 2008;16(9):414-9. https://doi.org/10.1016/j.tim.2008.06.001

98. Brock TD, Gustafson J. Ferric iron reduction by sulfur- and iron-oxidizing bacteria. Appl Environ Microb. 1976;32(4):567-71.

99. Hu HW, Zhang LM, Yuan CL, He JZ. Contrasting Euryarchaeota communities between upland and paddy soils exhibited similar pH-impacted biogeographic patterns. Soil Biol Biochem. 2013;64:18-27. https://doi.org/10. 1016/j.soilbio.2013.04.003.

100. Fuhrman JA, McCallum K, Davis AA. Phylogenetic diversity of subsurface marine microbial communities from the Atlantic and Pacific oceans. Appl Environ Microb. 1993;59(5):1294-302.

101. DeLong EF. Archaea in coastal marine environments. Proc Natl Acad Sci U S A. 1992:89(12):5685-9. https://doi.org/10.1073/pnas.89.12.5685.

102. Munson MA, Nedwell DB, Embley TM. Phylogenetic diversity of Archaea in sediment samples from a coastal salt marsh. Appl Environ Microb. 1997; 63(12):4729-33.

103. Horz HP, Conrads G. The discussion goes on: what is the role of Euryarchaeota in humans? Archaea. 2010;2010:967271-8. https://doi.org/10. 1155/2010/967271.

104. Roccarina D, Lauritano E, Gabrielli M, Franceschi F, Ojetti V, Gasbarrini A. The role of methane in intestinal diseases. Am J Gastroenterol. 2010;105:1250-6. https://doi.org/10.1038/ajg.2009.744

105. Nakamura N, Lin HC, McSweeney CS, Mackie Rl, Gaskins HR. Mechanisms of microbial hydrogen disposal in the human Colon and Implications for health and disease. Annu Rev Food Sci Technol. 2010;1 (1):363-95. https:// doi.org/10.1146/annurev.food.102308.124101.

106. Vianna ME, Conrads G, Gomes BP, Horz HP. Identification and quantification of archaea involved in primary endodontic infections. J Clin Microbiol. 2006; 44(4):1274-82. https://doi.org/10.1128/JCM.44.4.1274-1282.2006.
107. Auguet JC, Barberan A, Casamayor EO. Global ecological patterns in uncultured Archaea. ISME J. 2010;4(2):182-90. https://doi.org/10.1038/ ismej.2009.109.

108. Li CL, Jiang YT, Liu DL, Qian J, Liang JP, Shu R. Prevalence and quantification of the uncommon Archaea phylotype Thermoplasmata in chronic periodontitis. Arch Oral Biol. 2014;59(8):822-8. https://doi.org/10.1016/j. archoralbio.2014.05.011.

109. Horz H-P, Seyfarth I, Conrads G. McrA and 16S rRNA gene analysis suggests a novel lineage of Archaea phylogenetically affiliated with Thermoplasmatales in human subgingival plaque. Anaerobe. 2012;18(3): 373-7. https://doi.org/10.1016/j.anaerobe.2012.04.006

110. He J, Li Y, Cao Y, Xue J, Zhou X. The oral microbiome diversity and its relation to human diseases. Folia Microbiol. 2015;60(1):69-80. https://doi org/10.1007/s12223-014-0342-2.

111. Golyshina OV, Timmis KN. Ferroplasma and relatives, recently discovered cell wall-lacking archaea making a living in extremely acid, heavy metal-rich environments. Environ Microbiol. 2005;7(9):1277-88. https://doi.org/10.1111/ j.1462-2920.2005.00861.x.

112. Golyshina OV. Environmental, biogeographic, and biochemical patterns of archaea of the family Ferroplasmaceae. Appl Environ Microbiol. 2011;77(15): 5071-8. https://doi.org/10.1128/AEM.00726-11.

113. Golyshina OV, Yakimov MM, Lünsdorf $H$, Ferrer M, Nimtz M, Timmis KN, Wray V, Tindall BJ, Golyshin PN. Acidiplasma aeolicum gen. nov., sp. nov., a euryarchaeon of the family Ferroplasmaceae isolated from a hydrothermal pool, and transfer of Ferroplasma cupricumulans to Acidiplasma cupricumulans comb. nov. Int J Syst Evol Micr. 2009;59(11):2815-23. https:// doi.org/10.1099/ijs.0.009639-0.

114. Foster JA, McVey Neufeld K-A. Gut-brain axis: how the microbiome influences anxiety and depression. Trends Neurosci. 2013;36(5):305-12. https://doi.org/10.1016/j.tins.2013.01.005.

115. Manocha M, Khan WI. Serotonin and Gl disorders: an update on clinical and experimental studies. Clin Transl Gastroenterol. 2012;3(4):e13-e8. https://doi. org/10.1038/ctg.2012.8.

116. Wang H, Grahame-Smith DG. The effects of rubidium, caesium and quinine on 5-HT-mediated behaviour in rat and mouse-1. Rubidium. Neuropharmacology. 1992;31(5):413-419; doi: https://doi.org/10.1016/00283908(92)90077-3.

117. Reigstad CS, Salmonson CE, 3rd JFR, Szurszewski JH, Linden DR, Sonnenburg UL, Farrugia G, Kashyap PC. Gut microbes promote colonic serotonin production through an effect of short-chain fatty acids on enterochromaffin cells. FASEB J 2015;29(4):1395-1403; doi: https://doi.org/10.1096/fj.14-259598.

118. Yano JM, Yu K, Donaldson GP, Shastri GG, Ann P, Ma L, Nagler CR, Ismagilov RF, Mazmanian SK, Hsiao EY. Indigenous Bacteria from the Gut Microbiota Regulate Host Serotonin Biosynthesis. Cell. 2015;161(2):264-76. https://doi. org/10.1016/j.cell.2015.02.047.

119. Arnold BC, Beaver RJ. Estimation of the number of classes in a population. Biom J. 1988;30(4):413-24.

120. Schloss PD, Westcott SL, Ryabin T, Hall JR, Hartmann M, Hollister EB, Lesniewski RA, Oakley BB, Parks DH, Robinson CJ, et al. Introducing mothur: open-source, platform-independent, community-supported software for describing and comparing microbial communities. Appl Environ Microb. 2009;75(23):7537-41. https://doi.org/10.1128/AEM.01541-09.

\section{Publisher's Note}

Springer Nature remains neutral with regard to jurisdictional claims in published maps and institutional affiliations.

\section{Ready to submit your research? Choose BMC and benefit from:}

- fast, convenient online submission

- thorough peer review by experienced researchers in your field

- rapid publication on acceptance

- support for research data, including large and complex data types

- gold Open Access which fosters wider collaboration and increased citations

- maximum visibility for your research: over $100 \mathrm{M}$ website views per year

At BMC, research is always in progress.

Learn more biomedcentral.com/submissions 